\title{
EL PRECIO DEL ORO DURANTE LA GRAN RECESIÓN DESDE UNA PERSPECTIVA AUSTRIACA
}

FRANCISCO SAAVEDRA GONZÁLEZ*

Fecha de recepción: 11 de noviembre de 2013.

Fecha de aceptación: 26 de marzo de 2014.

Resumen: El oro ha sido desde el año 2008 hasta el 2013, años conocidos como la Gran Recesión, uno de los activos cuya evolución más interés ha despertado en los agentes económicos. Su análisis desde el origen tanto a nivel teórico como histórico, los hechos más importantes que han afectado a su precio desde 1972, la situación de su mercado en 2013 y los factores que han sido determinantes de su precio durante la Gran Recesión son el motivo fundamental de este artículo que, a la luz de la Escuela Austriaca lleva inexorablemente a las siguiente conclusión: el sistema monetario necesita del oro como respaldo; y de no llevarse a cabo un progresivo acercamiento hacia el patrón oro clásico, el oro seguirá siendo uno de los activos más eficaces contra la inflación monetaria y la incertidumbre generada endógenamente por el sistema monetario y bancario. La evolución de la economía y la del precio del oro dependerá de las decisiones que se tomen para enfrentarnos a estos graves defectos del sistema, y deben tenerse en cuenta las consecuencias tanto desde el punto de vista monetario y económico, como desde el ámbito de la moral.

Palabras clave: Dinero, Bancos Centrales, Refugio, Inflación, Devaluación, Producción, Demanda, Política Monetaria, Política Fiscal.

Clasificación JEL: B53, D49, E39, E42, E58.

Abstract: Since 2008 to 2013 , years known as the Great Recession, gold has been one of the assets whose evolution has aroused more interest on

\footnotetext{
* Programa del Máster en Economía de la Escuela Austriaca, Universidad Rey Juan Carlos (Madrid).

Private Banker in Credit Suisse Spain. francisco.saavedra@credit-suisse.com
} 
the economic agents. Its theoretical and historic analysis from its origin, the most important facts that have affected its price since 1972, its market situation in 2013 and the factors that have been determinant in its price during the Great Recession are the main reasons of this article which, under the Austrian School point of view, guide us inexorably to this conclusion: the monetary system needs gold as backing; if a progressive approach to the classic gold standard is not done, gold will continue being one of the most efficient asset against the monetary inflation and endogenous uncertainty created by monetary and banking system. The economy and gold price evolution will depend on the decisions taken to afford these great system faults, and must be borne in mind their impact from monetary and economic point of view and also from the moral field.

Key words: Money, Central Banks, Refuge, Inflation, Devaluation, Production, Demand, Monetary Policy, Fiscal Policy.

JEL Classification: B53, D49, E39, E42, E58.

El dinero surge a lo largo de la historia como un proceso evolutivo y espontáneo llevado a cabo por multitud de personas que buscaban intercambiar sus mercancías utilizando el bien más fácilmente intercambiable, con el fin de satisfacer mejor sus necesidades. ${ }^{1}$

En el antiguo Egipto el bien más fácilmente intercambiable fue el cereal (el trigo), en Mesopotamia fueron las ovejas (penuspecunia), en Asia Menor las piezas de metal y en la civilización Azteca los granos de cacao. La causa de esta búsqueda tiene su origen en el problema del trueque por la doble coincidencia de necesidades. Se demandaban los bienes más vendibles en el entorno porque eran medios de pago generalmente aceptados, así se favorecían el número de intercambios, que es el hecho que ha fomentado a lo largo de la historia la división y especialización del conocimiento y el desarrollo de la civilización y de la vida tanto cualitativa como cuantitativamente.

El dinero es un bien económico común y generalmente aceptado como medio de intercambio. Es la institución social por exce-

${ }^{1}$ Carl Menger (1871). 
lencia porque depura el resto de instituciones sociales (el lenguaje, el derecho y la moral) al permitir la multiplicación de los intercambios en la sociedad. El origen del dinero es el resultado de un proceso empresarial espontáneo, no deliberado ni fruto de un contrato social o una imposición gubernamental. Surge evolutivamente y exigió una cantidad tal de conocimiento práctico que hacía imposible su creación por un solo ser humano o un pueblo concreto (el mito de su invención por los fenicios). Sabemos que el dinero cumple mejor su papel de medio de intercambio cuanto mayor es su aceptación (como el lenguaje o el derecho) y que a pesar de las diferentes situaciones históricas de cada región, el dinero acabó preponderando con el tiempo siendo clave para el avance de la civilización.

El oro y también la plata en menor medida, a través del proceso dinámico social evolutivo y espontáneo fue escogido como dinero en la historia de la Humanidad. Los motivos de tal elección fueron los siguientes:

- Es un metal relativamente escaso, difícil de extraer y producir, por lo que tiene un valor alto y sirve como depósito de valor.

- Es homogéneo, no como los otros medios de intercambio utilizados previamente (ovejas, trigo, cacao, etc.). Además su densidad y peso fueron factores también determinantes para su elección.

- Es un metal blando y cuya ley es fácil de determinar. Su flexibilidad y ductilidad son características muy importantes respecto del resto de metales.

- Es inmutable y acumulable. Su resistencia contra el aire y otros muchos agentes es fundamental para cumplir su función.

Históricamente el oro ha sido considerado como el dinero por excelencia. $^{2}$

La revolución marginalista terminó con el holismo (la paradoja del valor: o todo el oro o todo el hierro) y con los errores teóricos de los neoclásicos, permitiendo mejor la comprensión de la

\footnotetext{
${ }^{2}$ Mises (1940), pp. 479 y ss.
} 
función esencial del medio de intercambio como bien intermedio que se adquiere para facilitar los intercambios por otros bienes de consumo o factores de producción.

Los motivos para la demanda de medios de intercambio han sido:

1. Solventar el problema del trueque y conseguir más fácilmente la satisfacción de las necesidades personales.

2. Los productos perecederos que por su naturaleza dificultaban mucho el intercambio a través del trueque.

3. El permitir afrontar mejor la incertidumbre inerradicable del futuro. La destrucción creativa fruto de la función empresarial innata y creativa del ser humano, se puede afrontar mejor mediante las instituciones sociales, entre las cuales está el dinero, que tiene una importancia vital y nos permite abordar la incertidumbre con mayores garantías de éxito para la consecución de nuestros fines subjetivos.

En cuanto a las características del dinero podemos afirmar que cualquier medio de intercambio debe ser un bien económico, y por lo tanto escaso. Cualquier cantidad de dinero cumple bien su función si es escasa. No somos más ricos porque haya más cantidad de oferta monetaria en circulación, y sin embargo, sabemos que los cambios en dicha oferta monetaria distorsionan los precios de los bienes y factores productivos. Estamos dispuestos a pagar un precio por el dinero porque lo valoramos, y el precio del dinero es su poder adquisitivo. El dinero está atesorado, es propiedad de alguien y siempre cumple su función tanto si está activo como «ocioso». En definitiva, demandamos riqueza, no dinero.

El mercado de dinero es todo aquel donde se intercambian bienes y servicios por dinero y donde se determina el precio del dinero (su capacidad adquisitiva). Y el precio del dinero está determinado por la oferta y la demanda. Los componentes de la demanda son tres: el industrial (como bien de consumo o de producción), el monetario que es el más importante (el dinero como medio de intercambio), y las expectativas.

El teorema regresivo del dinero explica que el precio del dinero, o su capacidad adquisitiva de hoy, lo determina la demanda 
de dinero de hoy; y la demanda de dinero de hoy depende de nuestra experiencia sobre el precio del dinero de ayer, y así sucesivamente hasta remontarse hasta cuando la única demanda de dinero era industrial.

La oferta de dinero actualmente, tras la expropiación del dinero privado a través del dinero fiduciario o fiat y las leyes de curso legal del papel moneda no convertible, depende de decisiones políticas, que pueden incrementarla inyectando dinero-deuda a través de tres procedimientos: La monetización del déficit público, la expansión del crédito y las compras a mercado abierto. Todos estos procedimientos se han llevado a cabo frecuentemente durante la Gran Recesión y en los años previos a la misma. ${ }^{3}$

Es importante sobre todo entender cuáles han sido los hechos más relevantes que han afectado al oro, al sistema monetaria y al sistema bancario desde el año 1900. Los repasamos a continuación ${ }^{4}$ :

— En 1900 la «US Gold Standard Act» estableció al oro como único estándar para redimir papel moneda (total convertibilidad).

— En 1913 la «Federal Reserve Act» creó la FED especificando que las emisiones de la Reserva Federal debían estar respaldadas en un $40 \%$ por oro.

- En 1914 el patrón oro fue suspendido durante la I Guerra Mundial hasta 1919.

— En 1925 la «British Gold Standard Act» estableció el patrón oro en el Reino Unido.

- En 1929 tuvo lugar la Gran Depresión.

- En 1931 el Reino Unido suspendió el patrón oro.

- En 1933 el Presidente Roosevelt prohibió la acumulación de monedas, lingotes y certificados de oro.

— En 1934 la «US Gold Reserve Act» obligó a todos los tenedores de oro, incluyendo a la Reserva Federal, a vender su oro al Tesoro de Estados Unidos. Paró la acuñación de monedas de oro y devaluó el dólar mediante un incremento del precio del oro desde 20,67 dólares por onza hasta 35 dólares la onza $(664,54$ dólares por kilogramo hasta 1.125,25 dólares por kilogramo).

\footnotetext{
${ }^{3}$ Mises (1940), pp. 491 y ss.

${ }^{4}$ Tobias Merath, Eliane Tanner y Stefan Braber (2010).
} 
- En 1937 el depositario de los lingotes, Fort Knox, fue creado como un departamento del Tesoro de Estados Unidos.

- En 1942 el Presidente Roosevelt ordenó el cierre de todas las minas de oro por la entrada de Estados Unidos en la II Guerra Mundial.

- En 1944 se firmaron los acuerdos de Bretón Woods vinculando el dólar americano al oro a través de una paridad fija. El dólar estadounidense obtuvo su privilegio de moneda reserva internacional. Se crearon el FMI y el Banco Mundial.

— En 1947 los laboratorios AT\&T Bell inventaron el primer transistor que allanó el camino para el uso generalizado del oro en la electrónica.

- En 1954 el mercado de oro en Londres volvió a funcionar tras su cierre durante la II Guerra Mundial.

— En 1960 el precio del oro en Londres se negoció temporalmente a 40 dólares estadounidenses por onza (1.286 dólares por kilogramo).

- En 1961 tanto Estados Unidos como otros siete países europeos se agruparon para defender en Londres el cambio establecido en 1934 de 35 dólares por onza (1.125,25 dólares por kilogramo). El Presidente Eisenhower prohibió a los residentes americanos la tenencia de oro.

- En 1964 comenzó la crisis de la libra esterlina, que duró hasta 1969.

— En 1967 Francia abandonó el «pool» de Londres de 1961.

- En 1968 el mercado de oro en Londres cerró durante dos semanas. El «pool» de Londres colapsó y surgió un sistema de fijación de precios del oro en dos niveles, monetario y no monetario. Se eliminó el respaldo de oro para las emisiones de la Reserva Federal.

- En 1971 el Presidente Nixon unilateralmente eliminó la convertibilidad del dólar americano en oro. El dólar americano se devaluó y aumentó el precio del oro hasta los 38 dólares por onza (1.221,7 dólares por kilogramo).

- En 1973 el valor monetario del oro se incrementó hasta los 42,22 dólares por onza (1.357,37 dólares por kilogramo). Las principales divisas comenzaron a fluctuar de forma independiente respecto del precio del oro. En junio alcanzó en el mercado 
de Londres los 120 dólares por onza (3.858 dólares por kilogramo).

- En 1975 la negociación con futuros sobre el oro comienza en Nueva York y en Chicago en el mercado de materias primas.

— En 1976 y hasta 1980 el FMI y numerosos bancos centrales vendieron una parte significativa de sus reservas en oro.

- En 1980 la altísima inflación que tuvo lugar desde 1976 en Estados Unidos y la invasión de la URSS de Afganistán impulsó el precio del oro hasta los 870 dólares por onza $(27.970,50$ dólares por kilogramo).

- En 1987 tuvo lugar el Lunes Negro.

- En 1993 se liberalizaron los mercados de oro en India y en Turquía.

— En 1996 y hasta 1999 varios bancos centrales comenzaron a vender su oro.

— En el 2000 estalló la burbuja «punto com» y comenzó un nuevo mercado alcista para el oro.

- En 2003 se puso en marcha el primer ETF de oro.

- En 2006 comenzó la crisis subprime en Estados Unidos.

- En 2007 estalló la crisis financiera y la posterior recesión económica conocida como «la Gran Recesión».

- En 2009 comenzaron a comprar oro los bancos centrales de países emergentes.

— En 2012 el precio del oro alcanzó los 1900 dólares por onza (61.085 dólares por kilogramo). Basilea III incluyó el oro de las reservas bancarias como parte del TIER 1 al 100\%. También el estado de Utah reconoció oficialmente como medios de pago el oro y la plata.

Además de estos acontecimientos históricos, los bancos centrales han firmado acuerdos internacionales desde el año 1999 que han afectado al precio del oro y que son los siguientes ${ }^{5}$ :

- En los acuerdos de los bancos centrales sobre el oro en 1999 decidieron mantener el oro como un elemento importante de

${ }^{5}$ José Luis Martínez Campuzano (2010). 
las reservas monetarias globales. Los bancos firmantes decidieron no entrar en el mercado como vendedores con la excepción de las ventas decididas en ese momento.

Las ventas anuales no excederían las 400 toneladas al año durante cinco años, no superando el límite de 2.000 toneladas como cifra total. Acordaron también no ampliar sus arrendamientos con opción de compra (leasing) sobre oro y no hacer uso de futuros y opciones durante ese periodo. Ese acuerdo sería revisado cada cinco años.

- En 2004 se hizo una declaración conjunta donde se mantenía el oro como elemento esencial de las reservas del sistema monetario global. Los firmantes acordaron un programa concertado de ventas de oro durante un periodo de cinco años, comenzando estas el 27 de septiembre de ese año. Las ventas no excederían las 500 toneladas al año y las 2.500 toneladas durante el periodo fijado. Acordaron también que tanto los arrendamientos con opción de compra como las operaciones con futuros y opciones no debían exceder el total de reservas en su poder a la fecha del acuerdo. Este acuerdo se revisaría a los cinco años también.

- En 2008 el FMI dio unas directrices para las ventas de oro reafirmando la importancia sistémica del mismo y la responsabilidad de evitar manipulaciones que afectarían transversalmente tanto a tenedores de oro como a productores, y también al mercado del oro.

- En 2009 renovaron el acuerdo anterior comprometiéndose a vender reservas con un máximo de 400 toneladas al año y 2.000 toneladas en total para los cinco años siguientes. También reconocieron la intención del FMI de vender 403 toneladas de oro y señalaron que esas ventas se incluirían en los límites anteriormente detallados.

- En 2012 Basilea III decidió incluir el oro en las reservas bancarias para el cómputo del TIER 1 al 100\% de su valor, equiparándolo con otros activos considerados de riesgo cero como los bonos soberanos AAA, el dinero en efectivo en dólares americanos o euros (anteriormente el oro computaba al 50\% y no hacía interesante para los bancos su acumulación). 


\section{I SITUACIÓN DEL MERCADO DEL ORO DURANTE LA GRAN RECESIÓN}

El mercado del oro es francamente pequeño en comparación con otros mercados. En los gráficos siguientes de 2009 se puede observar el peso tan pequeño del mercado del oro en comparación con la oferta monetaria global M3 o con el valor de los activos financieros o la capitalización de algunas compañías y sectores de la economía.

Los principales productores de oro actualmente son países emergentes como Sudáfrica, China, Perú y Rusia. Entre los países más desarrollados están Australia, Estados Unidos y Canadá (Gráfico 3).

Los principales tenedores de lingotes de oro son los países que históricamente han acumulado y mantenido las mayores reservas

GRÁFICO 1

EL PESO DE LA INVERSIÓN EN ORO ES MUY PEQUEÑO... TODAVÍA

\$ Trillion

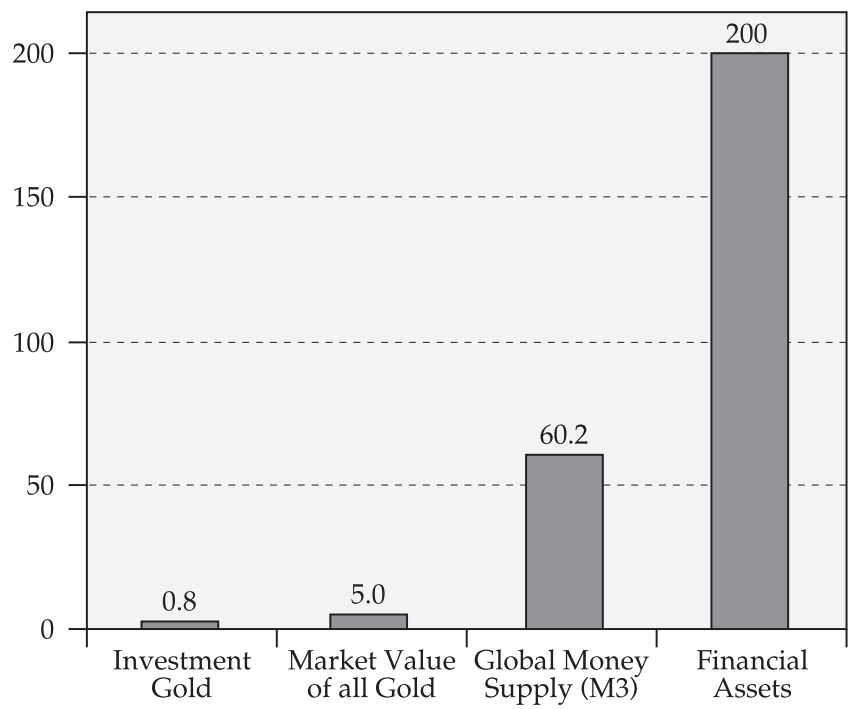

Fuente: www.agorafinancial.com 


\section{GRÁFICO 2}

CAPITALIZACIÓN DE MERCADO DE LA INDUSTRIA DEL ORO EN BILLONES DE DÓLARES AMERICANOS

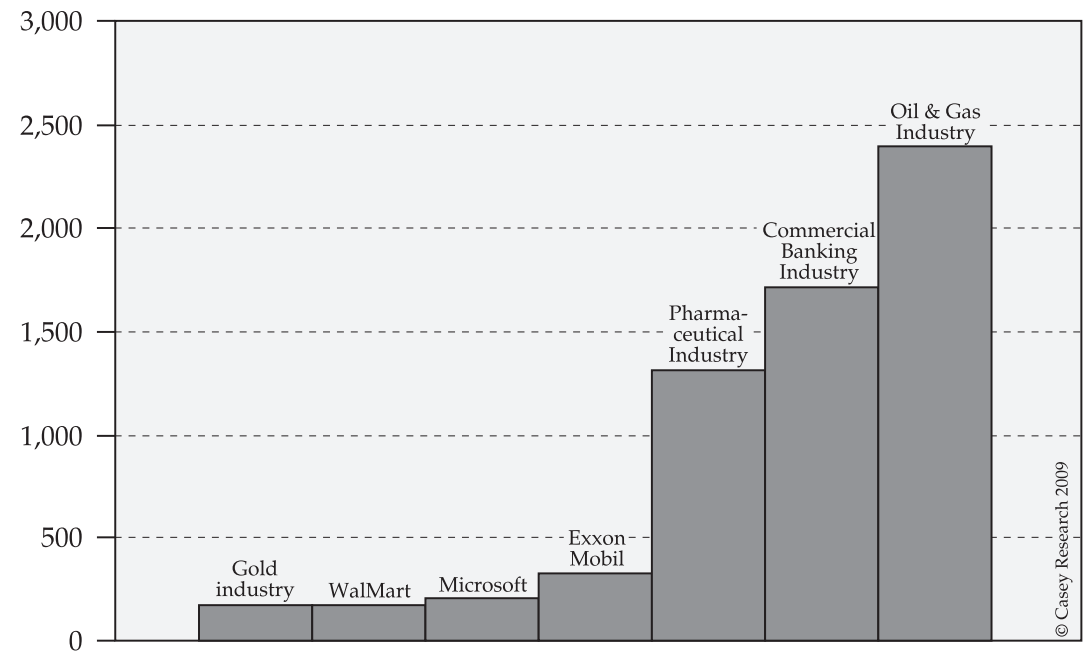

Fuente: Yahoo Finance, Fidelity.

\section{GRÁFICO 3}

PRODUCCIÓN MUNDIAL DE ORO

(Datos del año 2006 que muestran producción en kilogramos por país y año)

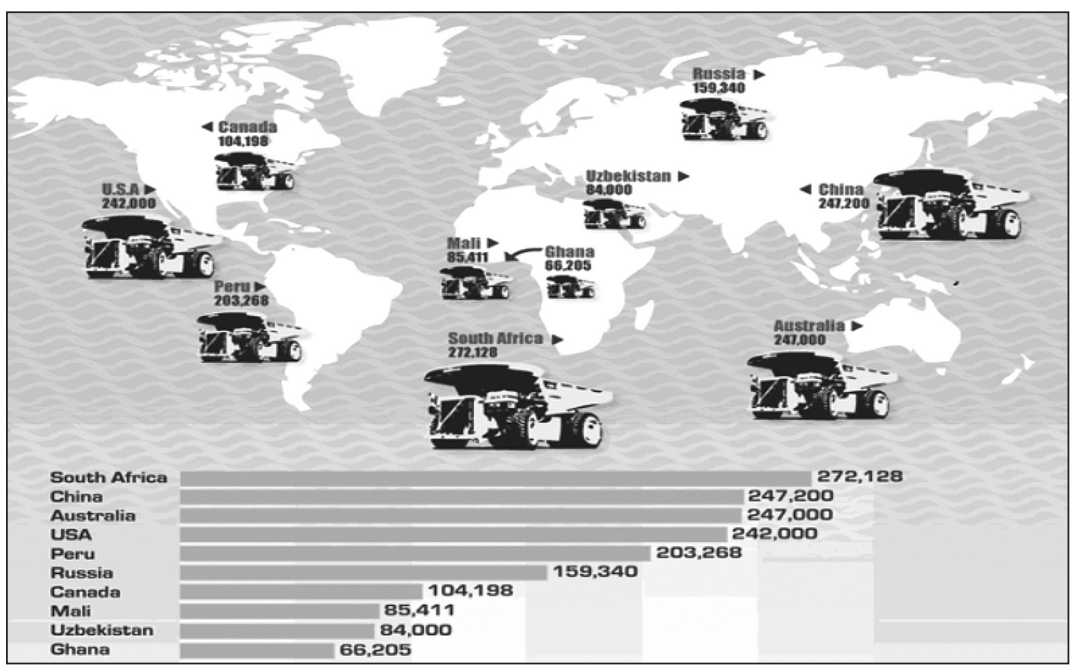


de oro mundial, como Estados Unidos, Alemania, Italia, Francia y el FMI. Sin embargo, es relevante también que un ETF de oro, SPDR Gold Shares, se ha convertido en uno de los mayores tenedores desde el año 2000. Por otro lado, y desde el 2009 es significativo el posicionamiento comprador de muchos países emergentes, entre los que destaca China, cuya aparición como uno de los mayores tenedores se ha producido en un breve espacio de tiempo, debido esencialmente a su necesidad de diversificar las grandes reservas en divisas que ha acumulado por su actividad exportadora (Gráfico 4).

La medida de peso de referencia en el mercado del oro es la onza troy, y el precio de la cotización se da en onzas troy. Un kilogramo de oro equivale a 32,15 onzas troy aproximadamente $(32,15074656862)$. La onza troy que cotiza en el mercado siempre se refiere a oro de 24 quilates (99\% de pureza).

Desde el año 2007 hasta el 2013, los impuestos a la producción de oro se han incrementado sustancialmente, haciendo que el coste de extracción en 2013 de cada onza sea aproximadamente de unos 1.300 dólares (41.796 dólares americanos por kilogramo). Con un

GRÁFICO 4

TENEDORES MUNDIALES DE ORO

(Reservas en kilogramos)

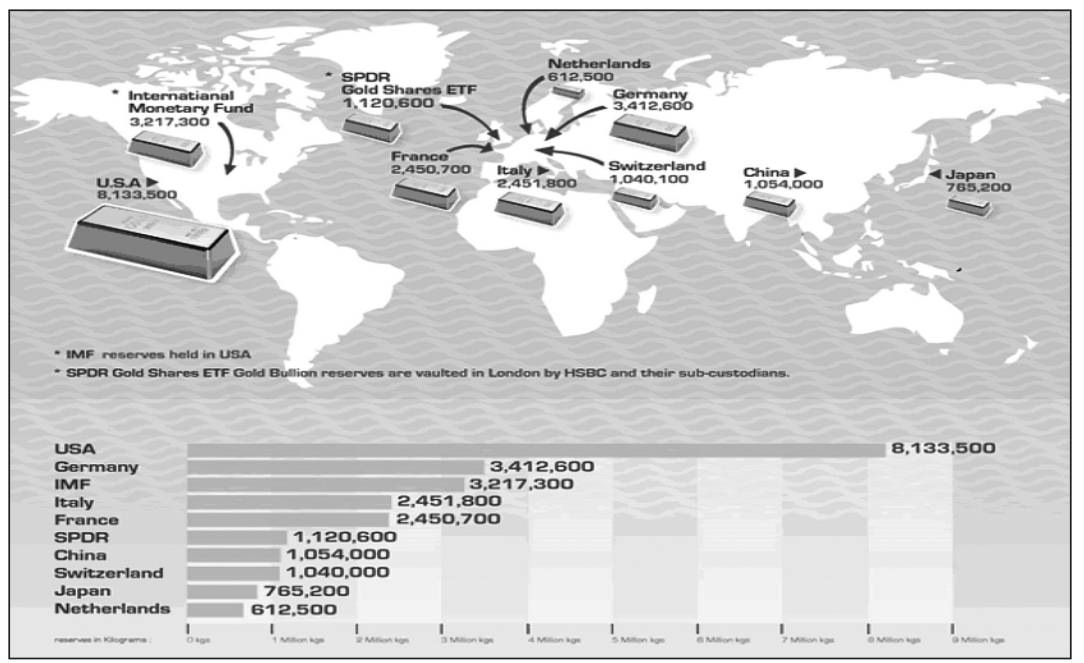


precio de mercado de 1.700 dólares por onza troy (54.656 dólares americanos por kilogramo) los productores tienen un beneficio razonable, por debajo de ese precio los productores no tienen incentivo suficiente para muchos de sus proyectos de extracción. ${ }^{6}$ (Gráfico 5).

Desde 1997 hasta 2013 se han producido 99 nuevos descubrimientos mineros que se estiman superiores a 2 millones de onzas (62,2 toneladas), pero desde el año 2008 estos descubrimientos han sido mínimos (Gráfico 6).

GRÁFICO 5

COSTE DE REPOSICIÓN DE UNA ONZA DE ORO

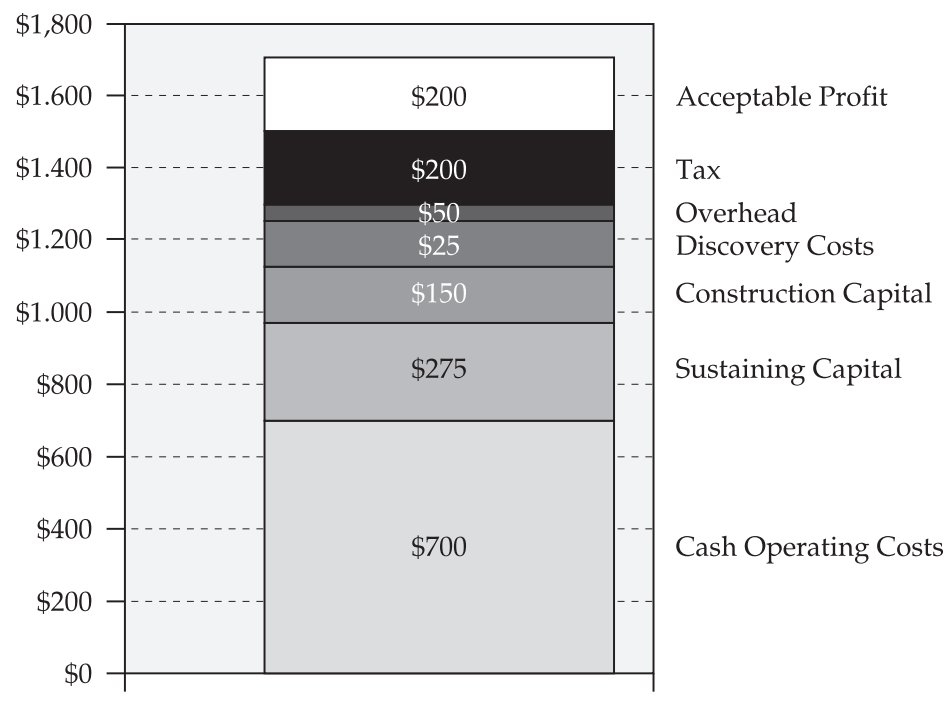

Fuente: CIBC World Markets.

${ }^{6}$ Frank Holmes (2012). 
GRÁFICO 6

ESCASEZ DE DESCUBRIMIENTOS SUPERIORES

A 3 MILLONES DE ONZAS

(En millones de onzas troy.

Un millón de onzas equivale a 31,1 toneladas)

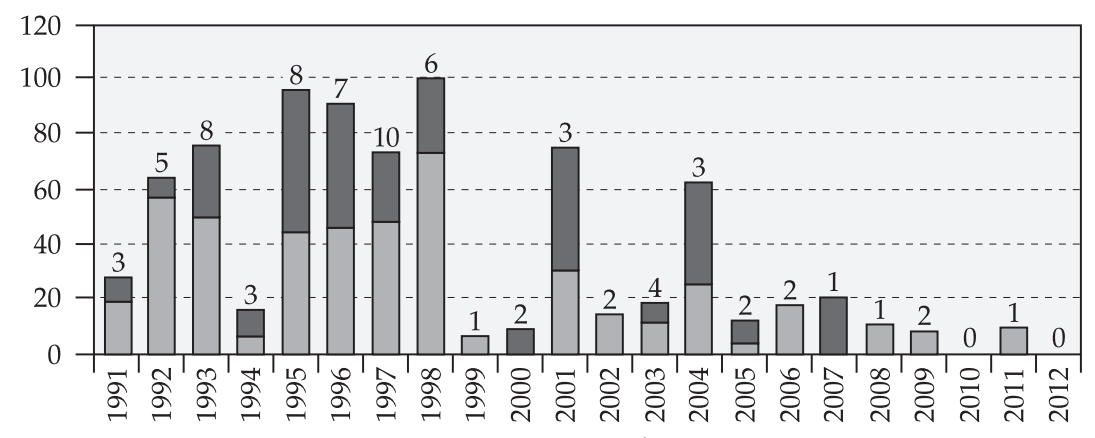

Discoveries In The Year

$\square$ Primanly Gold Only $\quad \square$ Copper Gold Porphyry

Fuente: Metals Economics CIBC.

II

FACTORES DETERMINANTES EN LA EVOLUCIÓN DEL PRECIO

El precio del oro ha evolucionado de forma espectacular desde el año 1972 (Bretton Woods II) hasta el año 2013, como se puede observar en el gráfico siguiente. Cuáles son los factores determinantes de su precio es lo que analizaremos a continuación. Los principales son el carácter de valor refugio que tiene el oro ante contextos de elevada incertidumbre (políticos, bélicos, etc.) y riesgos sistémicos del sistema monetario y/o bancario, su eficacia como cobertura contra la inflación monetaria provocada por el papel moneda no convertible y la actuación de los bancos centrales, la cobertura contra las devaluaciones de las divisas (especialmente el dólar estadounidense), y el componente cíclico de la industria y otros agentes que afectan a la demanda y a la oferta. 
GRÁFICO 7

PRECIO DEL ORO EN ONZAS DESDE 1970

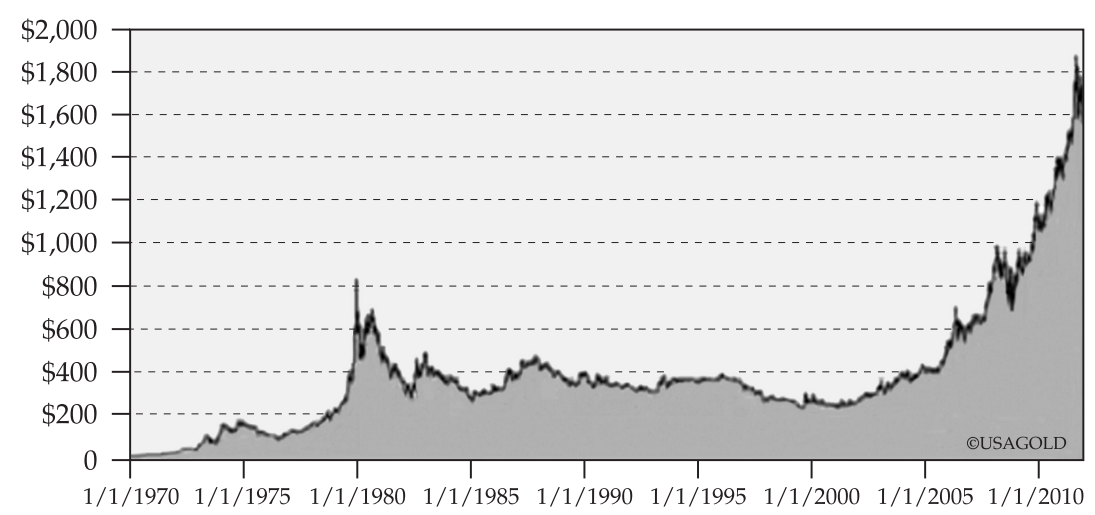

\section{El oro como valor refugio}

La vinculación de oro con la evolución de la acción humana a lo largo de la historia le han hecho valedor del calificativo de dinero por excelencia. Esto sigue siendo así en la actualidad a pesar de no estar monetizado tras la expropiación del dinero privado por parte de los gobiernos mediante las leyes de curso forzoso y de la imposición de un sistema monetario fiduciario o fiat, que carece del respaldo de activos reales. Por este motivo esencialmente, el oro sigue siendo el valor refugio por excelencia, y la evolución de su precio, especialmente desde el año 2000, está vinculado al exceso de deuda. Diferentes estimaciones en 2013 cuantifican el exceso de deuda en los mercados desarrollados en 8 trillones de dólares aproximadamente (nota: utilizaré la escala numérica norteamericana cuando me refiera a dólares norteamericanos y la europea cuando me refiera a euros. En la escala numérica norteamericana un trillón equivale a un billón en la europea). ${ }^{7}$ Los incrementos que se han producido tanto en la deuda pública como en la privada, llegando a niveles superiores al $250 \%$ del PIB, le han consagrado como refugio de valor ante la incertidumbre que ello genera. ${ }^{8}$ Los incrementos de los niveles de deuda pública y de déficit público

\footnotetext{
7 Andrew Garthwaite, Marina Pronina, Mark Richards y Sebastián Raedler (2012).

8 Antonio Merino (2012).
} 
son crecientes en muchas economías avanzadas y cuestionan la financiación de obligaciones de atención sanitaria, pensiones y un claramente sobredimensionado sector público. El círculo vicioso vuelve a repercutir en la banca a través del encarecimiento de los costes de financiación del sector público, que aumenta el coste también para el sector privado e induce a los bancos a emprender operaciones arriesgadas como la repignoración de activos o el trading con derivados. ${ }^{9}$

Especialmente desde el año 1971 muchos economistas, burócratas y gobernantes han entendido la política monetaria como una panacea capaz de arreglar los desequilibrios económicos. Uno de los grandes problemas de esta conducta es que desincentiva a los gobiernos de la aplicación de políticas fiscales y presupuestarias ortodoxas. Esto se ha podido contrastar en la Gran Recesión cuando el proceso ha llegado a la etapa en la que la credibilidad y sostenibilidad de las cuentas públicas se ha puesto en cuestión, dando comienzo a la crisis presupuestaria o de la deuda pública, y de las divisas o del propio sistema monetario fiduciario. Las estimaciones en 2013 confirman que el desempleo es explicado en un 60\% aproximadamente por los desequilibrios sectoriales. Es evidente que estos desajustes se produjeron previamente al estallido de la Gran Recesión, y fueron originados sobre todo por la expansión crediticia y el intervencionismo económico de los gobiernos. Las soluciones implementadas desde el año 2008 han aumentado los niveles de deuda precedente y es ilógico creer que un problema de excesiva deuda se puede solucionar con mas deuda (Gráfico 8).

El excesivo endeudamiento de la economía solo puede ser reducido mediante quiebras en una economía de libre mercado. En una economía muy intervenida y con un gran peso del sector público en ella, la historia nos muestra que en la mayoría de los casos se ha elegido la vía de la inflación y / o la devaluación de las monedas para reducir el endeudamiento. Las opciones para reducir la deuda, sin tanta simplificación son las siguientes:

1. Crecimiento económico.

2. Ajustes fiscales y austeridad.

9 Banco de Pagos Internacionales (2012). 


\section{GRÁFICO 8}

EL EXCESO DE APALANCAMIENTO EN LOS MERCADOS DESARROLLADOS SE ESTIMA EN 8 TRILLONES DE DÓLARES AMERICANOS

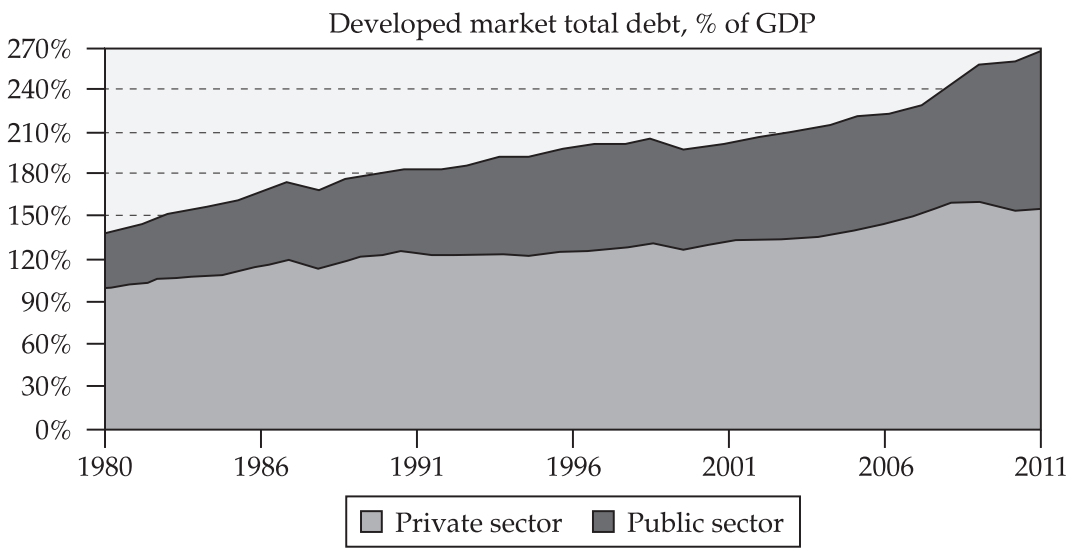

Fuente: Thomson Reuters, IMF, OECD, Eurostat, Credit Suisse research.

3. Reestructuración de la deuda mediante quitas.

4. Inflación.

5. Represión financiera que combina las opciones anteriores.

6. Devaluación de las divisas.

Tras el estallido de la Gran Recesión, los bancos centrales han llevado a cabo expansiones de sus balances sin precedentes. En 2013 en las economías avanzadas sus bancos centrales acumulan activos por un importe superior a los 18 trillones de dólares, que es más del 30\% del PIB mundial. En los países emergentes, especialmente el banco central chino, han acumulado en sus balances un peso superior al 40\% del PIB (Gráfico 9).

En el caso de China, su banco central ha acumulado reservas, sobre todo dólares estadounidenses, para mantener artificialmente bajo su tipo cambiario y las exportaciones en niveles elevados. Uno de los problemas de su balance es la gestión de dichas reservas, que han sido invertidas sobre todo en deuda del Tesoro de Estados Unidos, de ahí la necesidad acuciante de diversificarlas. Por otro lado, la creación de créditos en su divisa local ha generado problemas inflacionistas importantes y burbujas en 
GrÁFICO 9

\section{BALANCES DE BANCOS CENTRALES EN TRILLONES}

DE DÓLARES AMERICANOS

(BCE, Reserva Federal, Banco Central de Japón y Banco Central de China)

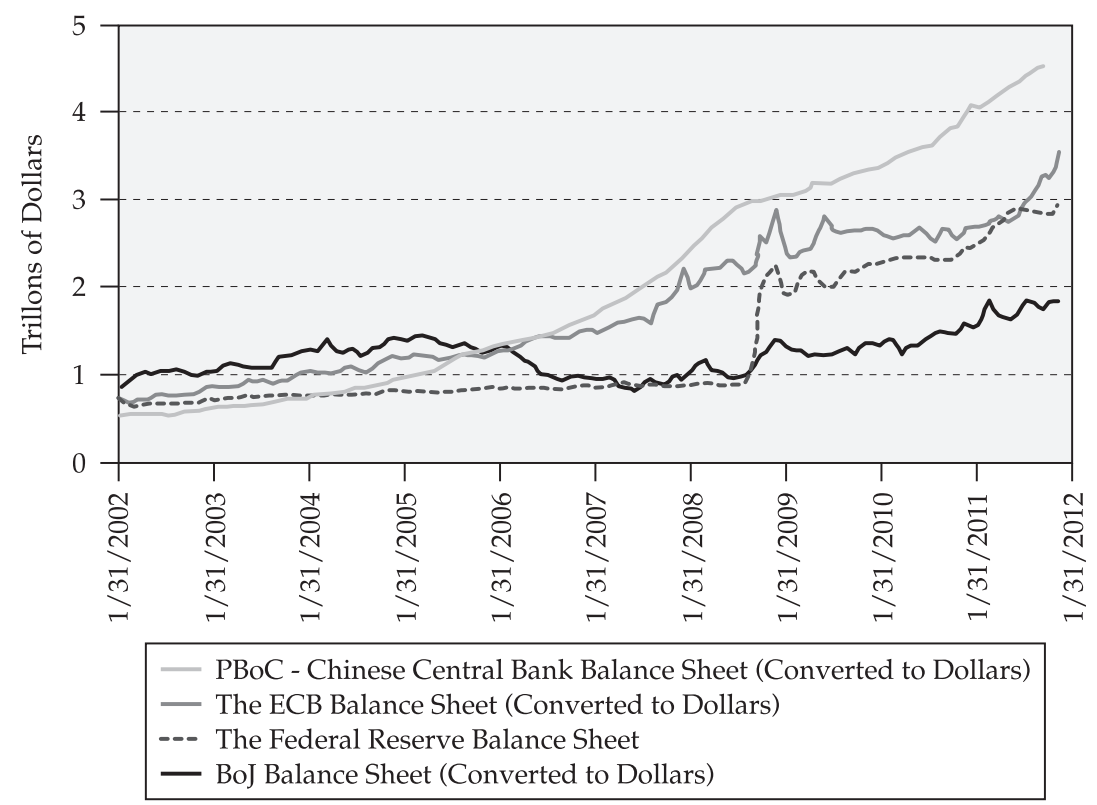

algunos activos inmobiliarios que están condicionando ya, tanto su política económica como la monetaria. Su sector financiero se ha resentido por ello y ante el intento de reducir la inflación ha aflorado un sistema bancario en la sombra que aumenta la incertidumbre sobre la sostenibilidad del tipo de políticas que han llevado a cabo hasta la fecha y sobre su crecimiento económico. ${ }^{10}$

Respecto de los bancos centrales de las economías avanzadas, estos se han decantado por efectuar sobre todo compras a mercado abierto (caso de la Reserva Federal, el Banco Central de Inglaterra o más recientemente del Banco Central de Japón) y también dotando de liquidez ilimitada al sector financiero mediante la

10 Andrew Filardo y James Yetman. (2011). 
aceptación de todo tipo de colaterales (caso del BCE). Las compras de activos tóxicos del sistema bancario y después de deuda pública a diferentes plazos ha reducido los tipos de interés a niveles excepcionalmente bajos, los menores de los últimos 150 años, y esto ha inflando el valor de los activos reales y monetarios, como se puede observar en los precios de los bonos a diferentes vencimientos, tanto públicos como privados, o los precios de la renta variable de los países que más han llevado a cabo este tipo de políticas expansivas. ${ }^{11} \mathrm{El}$ caso del $\mathrm{BCE}$, que es diferente, lo analizaremos más adelante (Gráfico 10).

La M1 en Estados Unidos, que incluye las monedas, los billetes y los depósitos a la vista en dólares americanos, se ha incrementado desde agosto del 2008 en un 73\%, alcanzando ya casi los 2,5 trillones. Esta expansión no tiene parangón (Gráfico 11).

El balance del Eurosistema es relativamente similar a los otros sistemas de economías avanzadas en cuanto al nivel de apalancamiento sobre PIB y al incremento del balance del banco central, pero las políticas monetarias del BCE han sido diferentes durante la Gran Recesión a las de sus homólogos anglosajones, básicamente porque no ha optado por la compra directa de activos de forma agresiva, sino que ha utilizado los colaterales para facilitar liquidez. ${ }^{12}$ (Gráfico 12).

Ante situaciones límite en los mercados de deuda pública europea durante los años 2011 y 2012 (crisis de deuda de los países periféricos) el BCE también ha realizado operaciones a mercado abierto para comprar activos directamente en el mercado secundario, pero a finales del año 2011 y principios del 2012 optó por dar liquidez a través de todo tipo de colaterales. Es cierto que tampoco es una política monetaria ortodoxa porque gran parte de los colaterales aceptados no han sido negociables en el mercado hasta 2013 como se puede ver en el Gráfico 13.

También las quitas que realizaba el BCE a los bonos y obligaciones de deuda de países en problemas distaba mucho de las que descontaban los rendimientos de los mismos y los seguros contra el impago de esas deudas en el mercado (Credit Default Swaps).

11 Markus H. Schiml (2013).

12 Carla Antunes, Amit Goel, Mahamed Souidi, Nick Gough y Justine Shih (2012). 
GrÁFICO 10

COMPOSICIÓN DEL ACTIVO DE LOS BANCOS CENTRALES DE LAS PRINCIPALES ECONOMÍAS DESARROLLADAS RESERVA FEDERAL

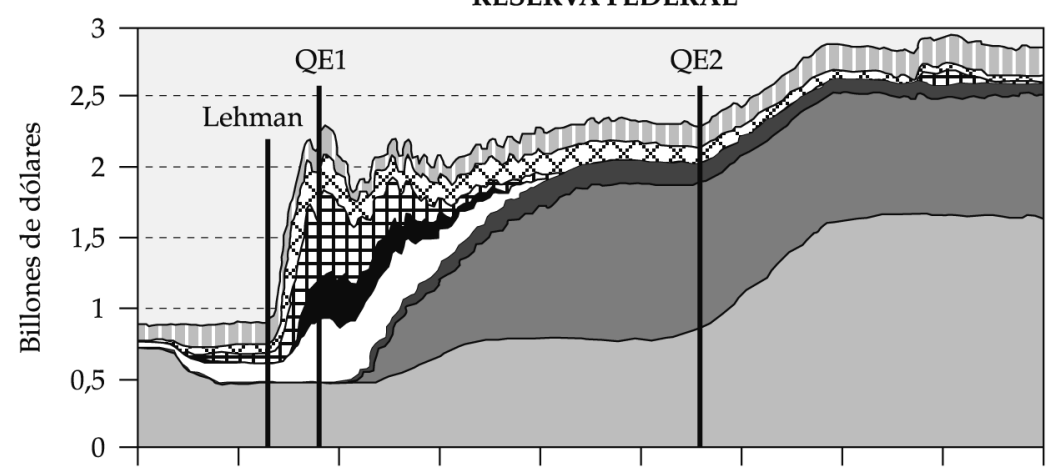

Ene.-08 Jul.-08 Ene.-09 Jul.-09 Ene.-10 Jul.-10 Ene.-11 Jul.-11 Ene.-12 Jul.-12

\begin{tabular}{|ll|}
\hline Otros & Resto de facilidades de liquidez \\
⿴囗十 Swaps con Bancos Centrales & Papel comercial \\
$\square$ Subastas a plazo & Deuda agencias \\
$\square$ Mortgages Backed Securities (MBS) & $\square$ Deuda pública \\
\hline
\end{tabular}

Fuente: Reserva Federal.

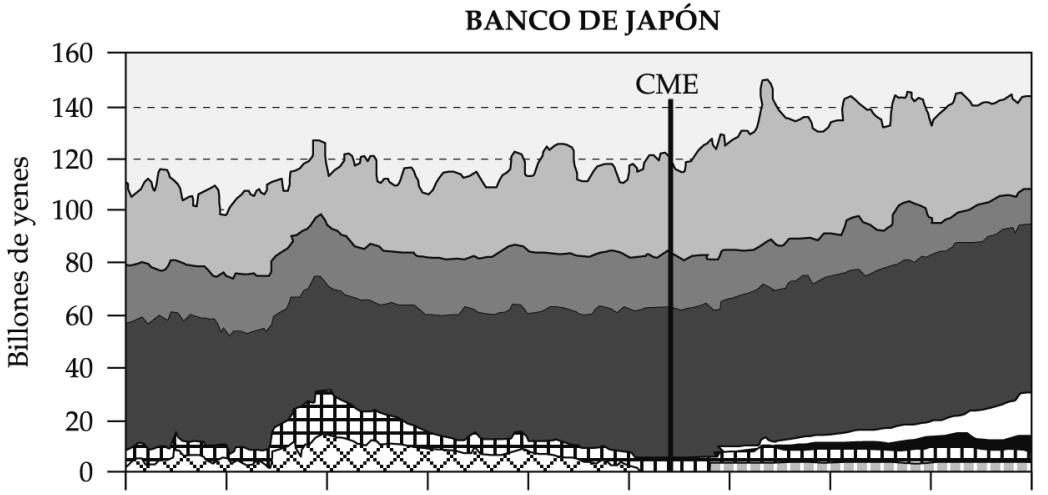

Ene.-08 Jul.-08 Ene.-09 Jul.-09 Ene.-10 Jul.-10 Ene.-11 Jul.-11 Ene.-12 Jul.-12

\begin{tabular}{|ll|}
\hline$\square$ Otros & $\square$ Repo \\
⿴囗十 Activos en moneda extranjera & $\square$ Deuda privada (PCA) \\
$\square$ Compra Deuda Pública (PCA) & $\square$ Bonos del Estado \\
$\square$ Letras del Tesoro & $\square$ Facilidad de liquidez \\
\hline
\end{tabular}

Nota: PCA = Programa de Compra de Activos.

Fuente: Banco de Japón. 
GRÁFICO 10

COMPOSICIÓN DEL ACTIVO DE LOS BANCOS CENTRALES DE LAS PRINCIPALES ECONOMÍAS DESARROLLADAS (continuación)

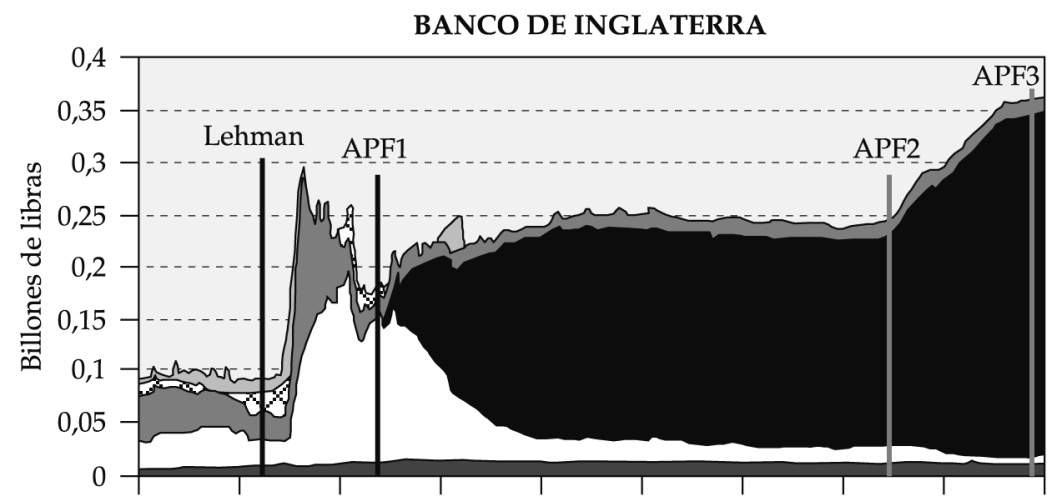

Ene.-08 Jul.-08 Ene.-09 Jul.-09 Ene.-10 Jul.-10 Ene.-11 Jul.-11 Ene.-12 Jul.-12

$\begin{array}{ll}\square \text { Op. de mercado abierto a corto plazo } & \text { Q Facilidad de crédito del Gobierno } \\ \square \text { Otros activos } & \text { Asset Purchase Facility (APF) } \\ \square \text { Repos a largo plazo } & \text { Otras operaciones de mercado }\end{array}$

Fuente: Banco de Inglaterra.

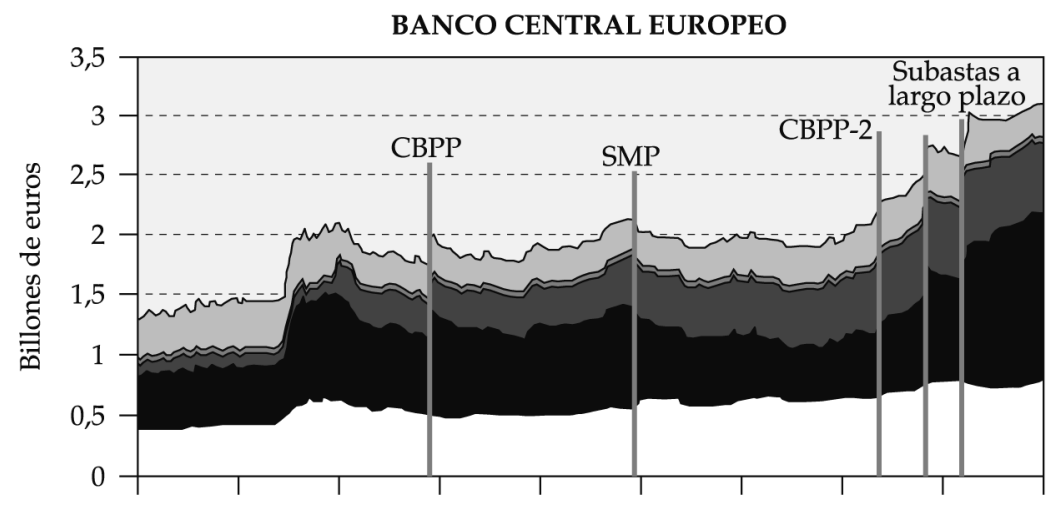

Ene.-08 Jul.-08 Ene.-09 Jul.-09 Ene.-10 Jul.-10 Ene.-11 Jul.-11 Ene.-12 Jul.-12

\begin{tabular}{|ll|}
\hline Otros activos & $\square$ Deuda Pública \\
$\square$ Valores & $\square$ Financiación a IFM \\
$\square$ Oro y activos en moneda extranjera & \\
\hline
\end{tabular}

Fuente: Banco Central Europeo. 


\section{GRÁFICO 11}

OFERTA DE DINERO (EN SENTIDO ESTRICTO) EN BILLONES DE DÓLARES AMERICANOS

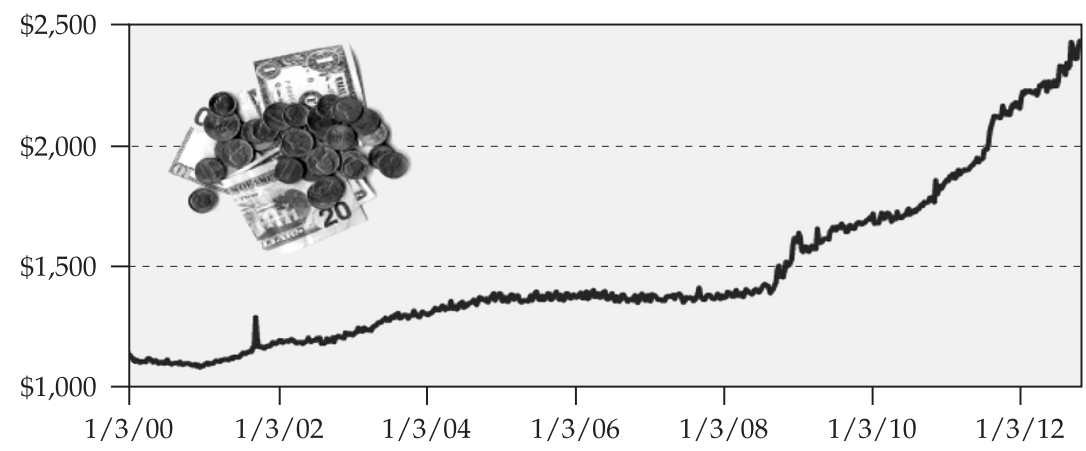

Fuente: FRED Graph from Federal Reserve Bank of St. Louis.

GrÁFICO 12

BALANCE DEL EUROSISTEMA

(Activos y pasivos a 01/06/2012: 3 billones de euros)

Assets

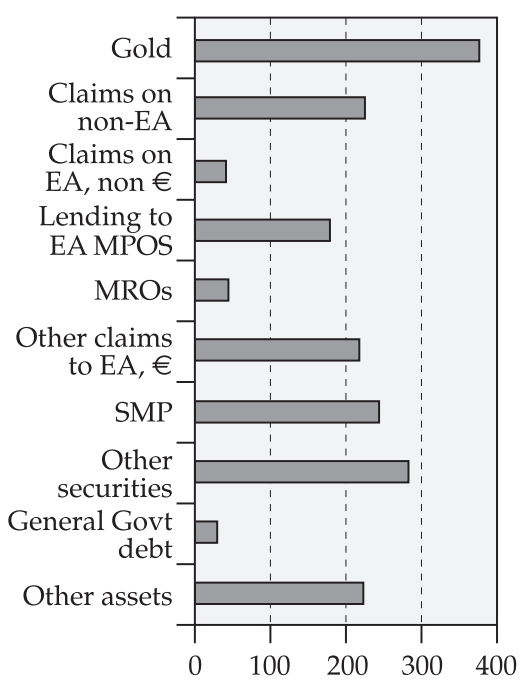

Liabilities

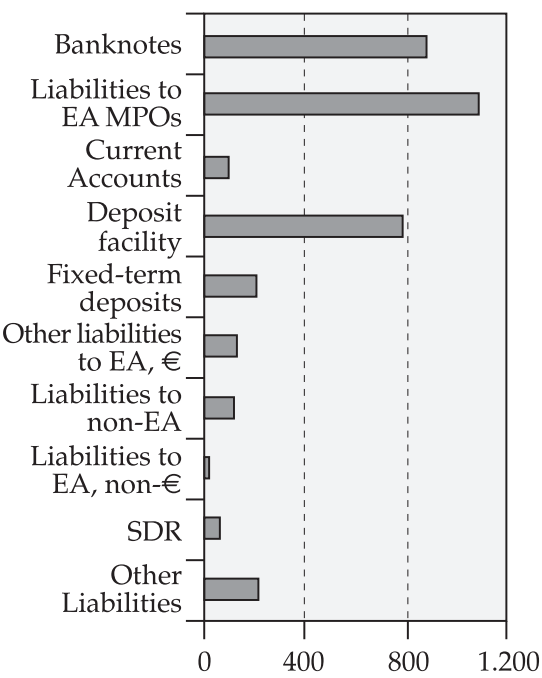

Nota: EA: Residentes en la zona Euro; SDR: Derechos Especiales de Giro asignados por el FMI.

Fuente: Credit Suisse, ECB. 


\section{GRÁFICO 13}

DESGLOSE DE GARANTÍAS (COLATERALES) EN EL BCE

(Garantías por valor de 1,79 billones de euros, por debajo de los 2 billones de euros de 2010)

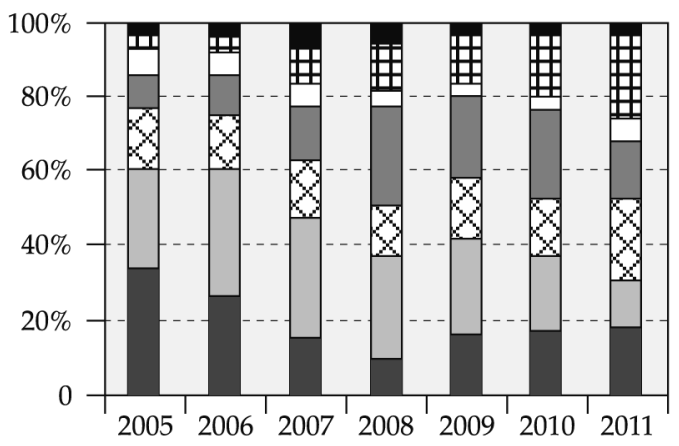

Other

$\square$ Non Marketable Assets

$\square$ Corporate bonds

Asset Backed Securities

$\square$ Covered bank bonds

$\square$ Uncovered band bonds

$\square$ General Govt Debt

Fuente: Credit Suisse, ECB annual report 2011.

La heterodoxia y laxitud se han puesto de manifiesto durante la Gran Recesión a través de estas decisiones del BCE, pero no es comparable a lo realizado por los bancos centrales anglosajones (Tabla 1).

Otro punto, y quizá uno de los más relevantes de cara al futuro, determinante del oro como valor refugio y de su precio, es el mercado de derivados. El hecho histórico que explica enormemente este punto fue la abolición de la ley Glass Steagall el 12

TABLA 1

LAS QUITAS EN LOS COLATERALES SON MUCHOS MENORES QUE LAS PÉRDIDAS IMPLÍCITAS QUE REFLEJAN TANTO EL MERCADO COMO LOS CDSs

\begin{tabular}{|c|c|c|c|c|c|c|}
\hline Sovereing & $\begin{array}{l}\text { Credit } \\
\text { rating }\end{array}$ & $\begin{array}{l}\text { 10-year } \\
\text { bond yield }\end{array}$ & $\begin{array}{c}10 y \text { CDS } \\
\text { spreads }\end{array}$ & $\begin{array}{c}E C B \\
\text { haircut }\end{array}$ & $\begin{array}{l}\text { Haircut } \\
\text { 10y bond } \\
\text { yields }\end{array}$ & $\begin{array}{l}\text { Iplied by } \\
10 y \text { CDS }\end{array}$ \\
\hline Greece & $\mathrm{CC}$ & $31.2 \%$ & na & $9.0 \%$ & $93 \%$ & na \\
\hline Portugal & BB & $11.1 \%$ & 24 & $9.0 \%$ & $59 \%$ & $81 \%$ \\
\hline Ireland & $\mathrm{BBB}+$ & $6.8 \%$ & 43 & $9.0 \%$ & $38 \%$ & $57 \%$ \\
\hline Italy & $\mathrm{BBB}+$ & $5.1 \%$ & 54 & $9.0 \%$ & $27 \%$ & $49 \%$ \\
\hline Spain & A & $5.3 \%$ & 48 & $4.0 \%$ & $29 \%$ & $44 \%$ \\
\hline France & $\mathrm{AA}+$ & $2.9 \%$ & 72 & $4.0 \%$ & $10 \%$ & $28 \%$ \\
\hline
\end{tabular}


de noviembre de 1999 por la administración Clinton. La ley Glass Steagall separaba totalmente la banca de depósito o comercial de la banca de inversión, creó un sistema bancario formado por bancos de ámbito nacional, estatal y local, y vetó la participación de los banqueros en consejos de administración de empresas industriales, comerciales y de servicios. ${ }^{13}$ Desde la abolición de la ley, los bancos pudieron tomar mas riesgos y apalancarse mas a través de filiales y del mercado OTC (Over The Counter). En 2013 y solo en Estados Unidos, el volumen nocional de los mismos asciende a 220 trillones de dólares estadounidenses, siendo el $90 \%$ de las posiciones a menos de un año. Además la concentración en cinco entidades bancarias del $97 \%$ de este volumen justifica el «demasiado grandes para caer» de estas instituciones. En el año 2013 Deutsche Bank ha informado de una exposición en el mercado OTC superior a 55 trillones de dólares estadounidenses. JP Morgan Chase tiene una exposición de 53 trillones de dólares estadounidenses. El PIB de Alemania es de 2,7 trillones USD en 2013. La magnitud de lo que implica el mercado OTC en el balance del sistema bancario es difícil de comprender. ${ }^{14}$ (Gráfico 14).

El mercado de derivados también ha afectado sustancialmente al mercado del oro, ya que desde el año 2004 ha dejado de ser un mercado básicamente de operaciones al contado para convertirse en un mercado principalmente de derivados. Desde el año 2008, la negociación del oro a través de futuros ha representado más del $60 \%$ del total negociado. ${ }^{15}$ (Gráfico 15).

Es evidente que unas condiciones monetarias laxas encubren problemas estructurales y retrasan el ajuste en los balances del sector público, de los bancos y del resto de agentes de la economía. ${ }^{16}$ También reducen el margen de intermediación de los bancos y su rentabilidad al bajar artificialmente los tipos de interés en todos los plazos. Este problema de márgenes también afecta a las aseguradoras y fondos de pensiones por los bajos rendimientos de la renta fija y el incremento del riesgo.

\footnotetext{
13 Ty Andros (2012).

14 Comptroller of the currency administrator of national banks (2012).

15 Tom Kendall (2012)

16 Jesús Huerta de Soto (1998).
} 
GRÁFICO 14

NOCIONAL EN DERIVADOS SEGÚN SU USO

(Asegurados por Bancos Comerciales y Asociaciones de Ahorro de Estados Unidos)

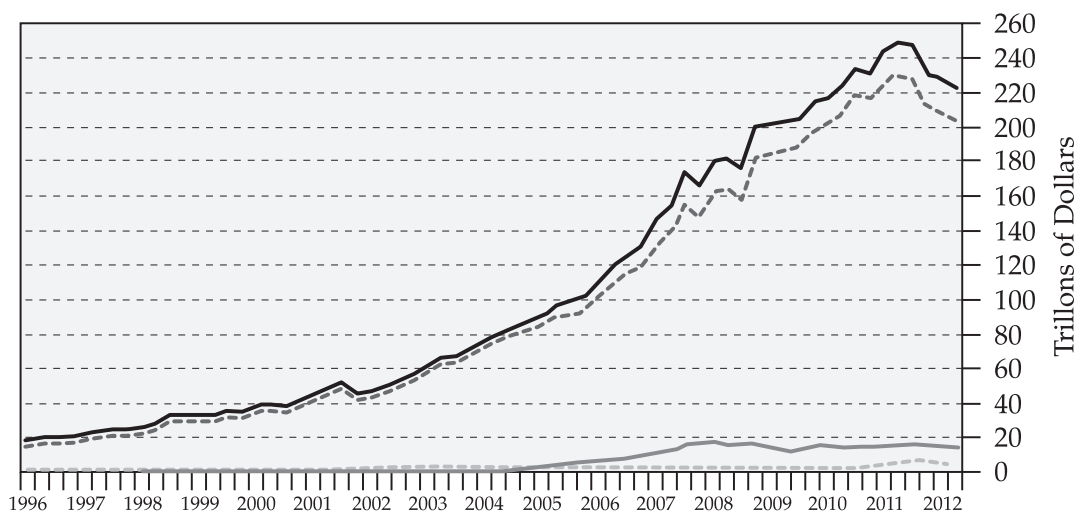

- Total Notionals -.- Dealer (Trading) End user (Non-trading) — Credit Derivates

GRÁFICO 15

VOLUMEN E IMPORTE ANUAL NEGOCIADO EN EL MERCADO DE ORO DE SHANGHAI

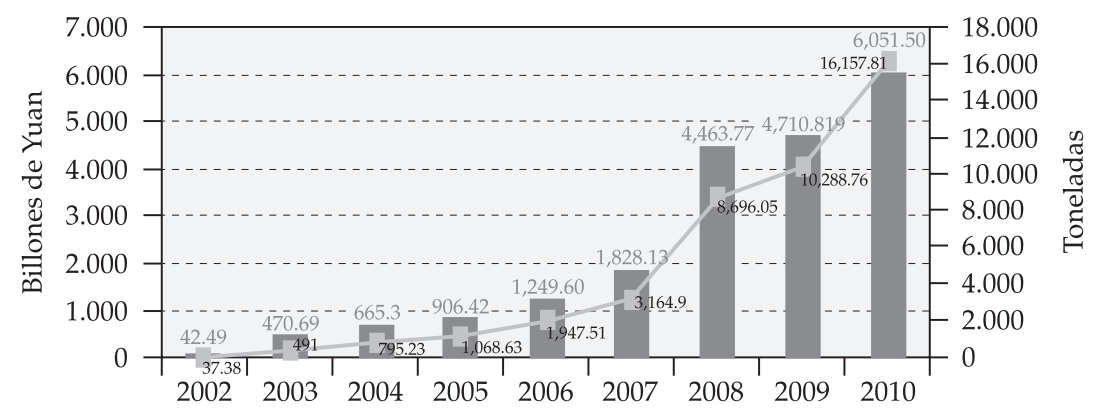

Respecto del incentivo que genera esta política monetaria en muchos agentes para una excesiva asunción de riesgo, los bancos se convierten necesariamente en actores principales. El sistema financiero global a principios de 2013, en estimaciones agregadas, está formado por 120 trillones de dólares en créditos respaldados por 8 trillones en reservas. Si incluimos estimaciones de la 
repignoración de activos y el sistema bancario en la sombra llegamos a un apalancamiento superior a 20 veces reservas. ${ }^{17}$ Pretender que los bancos centrales sean las instituciones donde toda la deuda tóxica e impagable de la economía se elimine mediante la monetización es una quimera. ${ }^{18}$ Pretender también que la regulación del mercado OTC o que mayores requisitos de capital y liquidez mediante Basilea III solucionen definitivamente estos problemas es una utopía. El 30 de junio de 2011 el Comité de Supervisión Bancaria de Basilea informó de que aproximadamente la mitad de los 205 bancos objeto de estudio debían realizar ajustes en sus actividades, reducir descalces de plazos o incrementar activos líquidos o financiación a largo plazo para atender a los cambios normativos en materia de liquidez. Estos bancos tenían un déficit de 1,76 billones de euros en activos líquidos y 2,78 billones de euros en financiación estable. ${ }^{19}$

Todo lo analizado del oro como valor refugio ha sido realizado desde el punto de vista económico y monetario, y ayuda en la comprensión de porqué el oro lo es, y de cómo durante Gran Recesión esta consideración ha sido un factor determinante de su precio. Sin entrar en cuestiones de geopolítica, ni en cómo afectan los conflictos bélicos, cuestiones que también influyen notablemente en el precio del oro, la incertidumbre, incluso la amenaza que supone el sistema monetario fiat y el sistema bancario, como los ciclos que provoca en economía real creando burbuja tras burbuja, seguirán haciendo del oro un valor refugio.

\section{El oro como cobertura contra la inflación}

La inflación ha sido el recurso más frecuente de los gobernantes para intentar «solucionar» los desequilibrios económicos, y los problemas políticos y sociales durante siglos. ${ }^{20}$ (Gráfico 16).

Las tasas de inflación oficiales han estado relativamente bajas desde 1990, pero la metodología del cálculo se ha cambiado en

\footnotetext{
17 Lauren R. Rublin (2012).

18 Mohamed A. El-Erian (2012).

19 William A. Allen y Richhild Moessner (2012).

${ }^{20}$ Murray N. Rothbard (1995).
} 
GRÁFICO 16

TASA DE INFLACIÓN DE ESTADOS UNIDOS

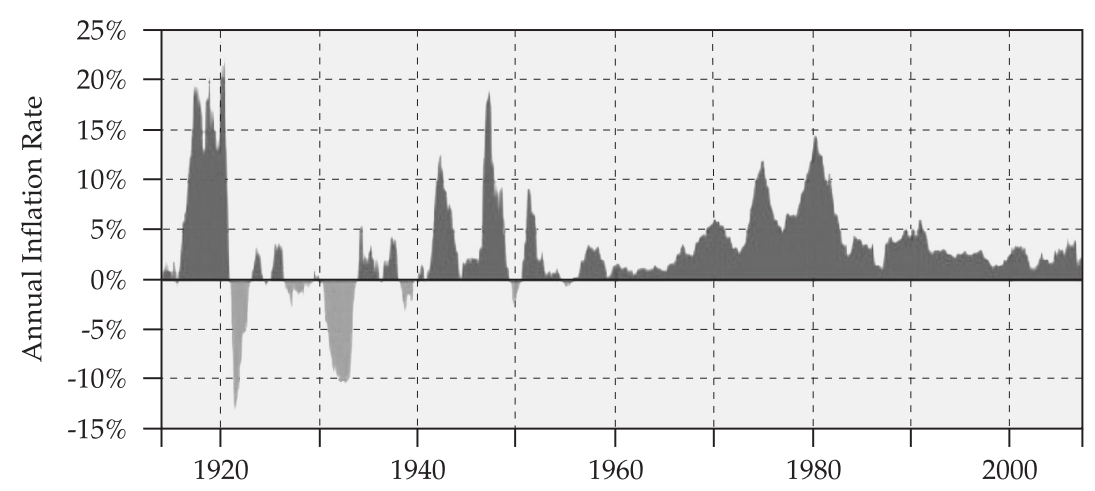

repetidas ocasiones con la finalidad de reducir el resultado final del dato oficial. Si se aplicasen las anteriores metodologías el resultado sería muy diferente y el dato en 2013 sería del 9\% aproximadamente, frente a un 1,5\% del dato oficial (Gráfico 17).

\section{GRÁFICO 17}

INFLACIÓN - DATO OFICIAL VS DATO ALTERNATIVO DE SHADOWSTATS

(Basado en la metodología de cálculo oficial de 1980)

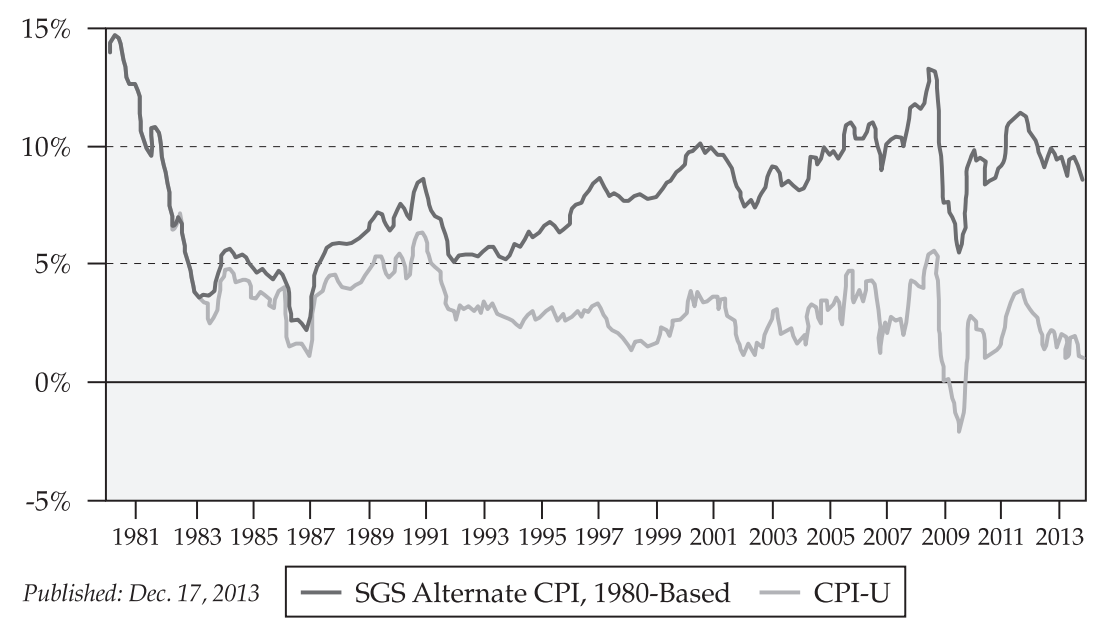

Fuente: shadowstats.com. 
El mantenimiento de un sistema monetario fiat desde el Bretton Woods II ha sido posible también gracias a la manipulación de otra variable fundamental de la economía totalmente vinculada a la inflación: los tipos de interés. No solo se ha tratado de afectar al tipo de interés a corto plazo (durante la Gran Recesión en niveles cero) sino a los tipos de interés a distintos plazos. De lo que estamos hablando es de la represión financiera, ya que los tipos de interés reales son negativos o muy negativos en todas las economías avanzadas. ${ }^{21}$ (Gráfico 18 ).

La manipulación de los tipos de interés de una forma tan agresiva ha generado grandes distorsiones y desequilibrios en la estructura productiva a partir de la década de los 90, ya que esta variable es la herramienta esencial para un correcto cálculo económico inter-temporal de todos los agentes económicos. La inflación y la creación de burbujas son las principales consecuencias de los niveles de tipos de interés artificialmente bajos, pero no las únicas. Con tipos de interés reales negativos se desincentiva el saneamiento de balances en el sector privado y la reducción de las necesidades de financiación en el sector público (Gráfico 19).

\section{GRÁFICO 18}

TIPOS DE INTERÉS REALES

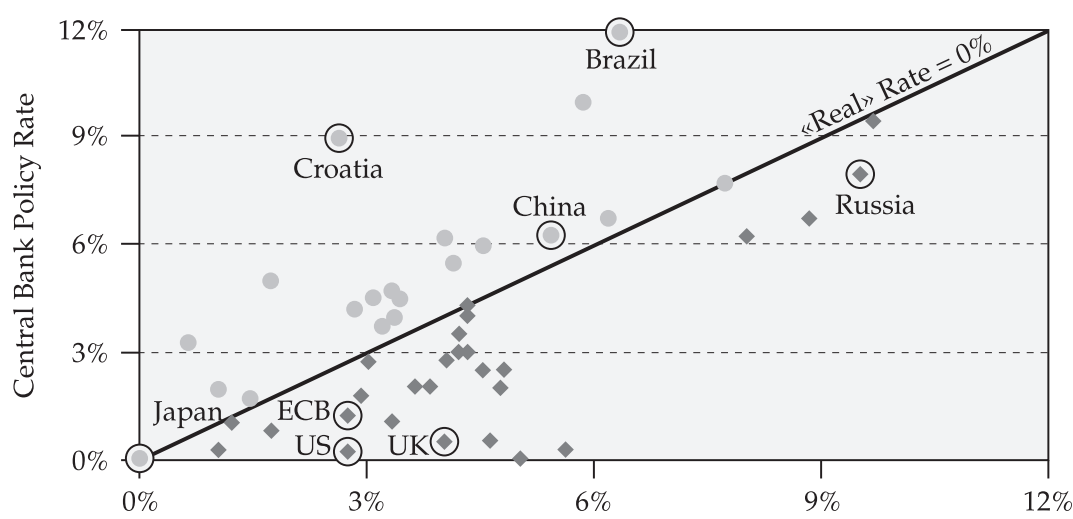

Fuente: Bloomberg, Catalpa.

${ }^{21}$ Bill Gross (2012). 
GRÁFICO 19

RENDIMIENTO REAL DE LOS BONOS A LARGO PLAZO DE ESTADOS UNIDOS

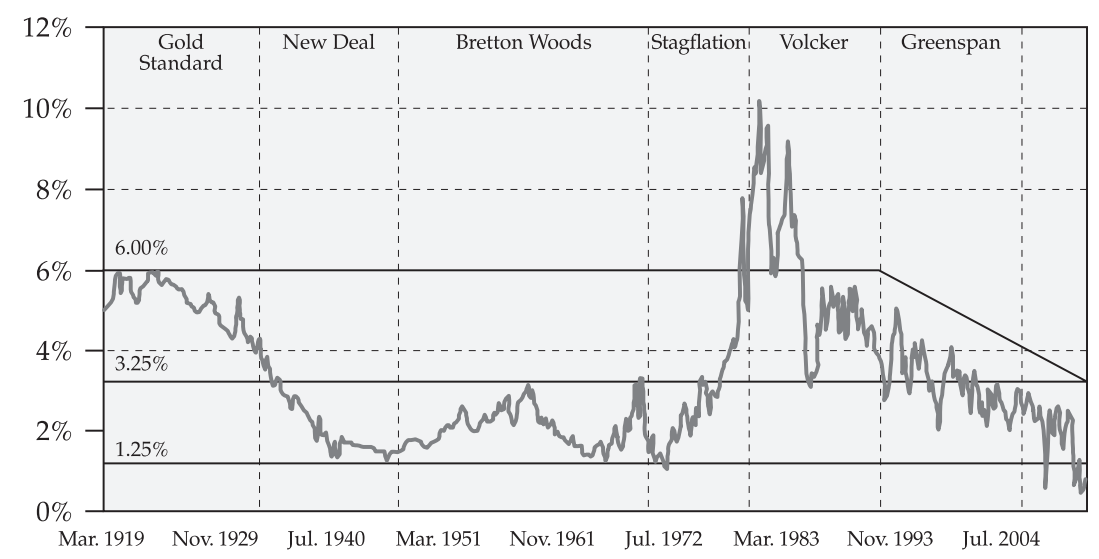

Fuente: Credit Suisse, Thomson Reuters Data Stream.

Las consecuencias de estas manipulaciones inflacionistas son extensivas a las materias primas y a todo tipo de activos. De hecho según el Banco de Inglaterra, en su publicación del 12 de julio de 2012, los programas de compra del banco central permiten la consecución de los objetivos del Gobierno mediante la inflación de los precios de los bonos y las acciones. ${ }^{22}$ Los tipos de cambio flexibles favorecen la devaluación competitiva y simultáneamente una reducción de deuda en términos relativos mediante inflación. Otros casos de inflación y burbujas en activos inmobiliarios los hemos visto en España e Irlanda. Sus consecuencias las hemos observado con claridad durante la Gran Recesión. ${ }^{23}$

Políticamente lo más fácil es optar por la solución de los problemas a través de la inflación. Durante los siglos XX y XXI ha sido la fórmula utilizada más frecuentemente por los gobernantes en general, pero queda demostrado por los economistas austriacos principalmente, que no resuelve los desequilibrios económicos sino que los enquista postergando el ajuste de balances y suponiendo un coste de oportunidad enorme. La inflación la provocan

\footnotetext{
22 Bank of England (2012).

${ }^{23}$ Pierre-Olivier Beffy, Amelie de Montchalin y Radica Kak (2012).
} 
los gobiernos a través de las manipulaciones que hemos comentado, especialmente a través del banco central de turno.

Además el pensamiento de grandes economistas de la Escuela Austriaca afirma que el inflacionismo es esencialmente antidemocrático. La mayoría de los escolásticos también consideraron inmoral destruir el valor intrínseco de la moneda (cuando contenía metal precioso) y la consiguiente inflación que ello provocaba. En el las últimas décadas hemos contrastado como la democracia se ha corrompido por la acción política, que ha utilizado la inflación y la manipulación monetaria para ocultar su demagogia e irresponsabilidad. El gran riesgo de que una espiral inflacionista desemboque en estanflación o incluso en hiperinflación no se puede obviar. La Alemania de entreguerras o la situación de Zimbawe son casos relativamente recientes como para pensar que su repetición es imposible. El ritmo de drenaje de la inmensa liquidez inyectada por los bancos centrales durante la Gran Recesión será clave para evitar estos escenarios, pero normalmente toman decisiones con retraso respecto de las burbujas que crea la expansión crediticia y su consecuencia más injusta para los más débiles: la inflación, el constante trasvase de valor del acreedor al deudor. ${ }^{24}$

El oro es una cobertura contra la inflación a largo plazo, basta ver el gráfico siguiente que compara inflación en Reino Unido y precio del oro en libras desde el año 1264.

\section{El dólar y la devaluación de las divisas}

Totalmente relacionado con todo lo anterior está una de las acciones políticas y monetarias más criticadas por la Escuela Austriaca: la devaluación. Inflación y devaluación son dos caras de la misma moneda. Junto con el recurso de inflacionar, el de devaluar es el más frecuentemente utilizado por los gobiernos y es esencialmente inmoral.

Respecto del oro y el dólar estadounidense y su estatus de moneda reserva mundial, debemos hacer una pequeña reseña ya que,

${ }^{24}$ Murray N. Rothbard (1995). 


\section{GRÁFICO 20}

\section{PRECIO DEL ORO EN LIBRAS ESTERLINAS VS. INFLACIÓN EN REINO UNIDO}

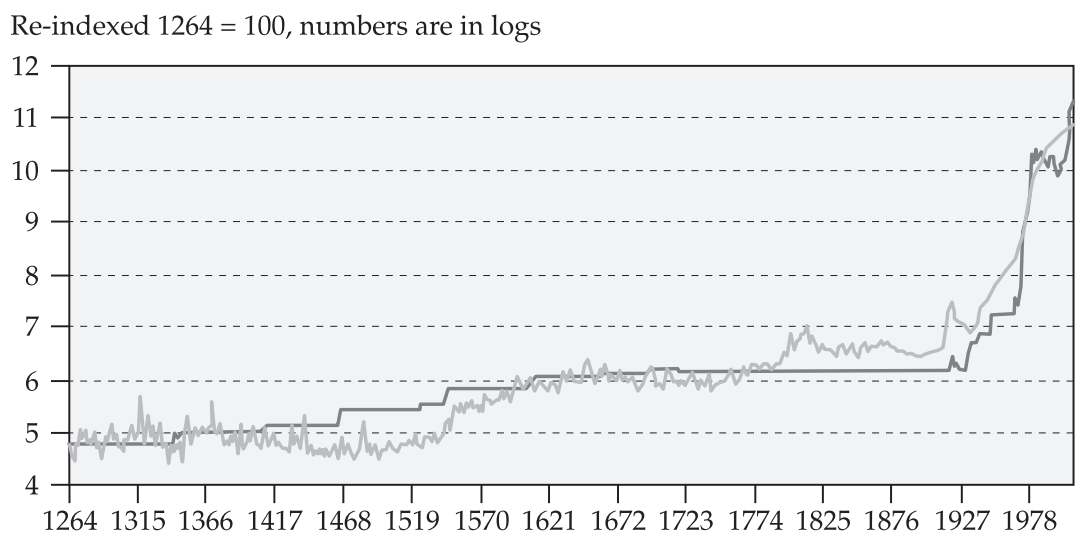

$$
\text { - Gold in GBP - UK CPI }
$$

como hemos podido recordar previamente, en varias ocasiones en el siglo XX se hicieron devaluaciones. Las consecuencias de las devaluaciones continuas de la Reserva Federal se observan en el hundimiento del poder adquisitivo de un dólar americano en términos de oro desde el año 1970, que se ha reducido en un 83\% aproximadamente. ${ }^{25}$ (Gráficos 21, 22 y 23).

\section{GRÁFICO 21}

\section{PÉRDIDA DE LA CAPACIDAD ADQUISITIVA}

DEL DÓLAR ESTADOUNIDENSE

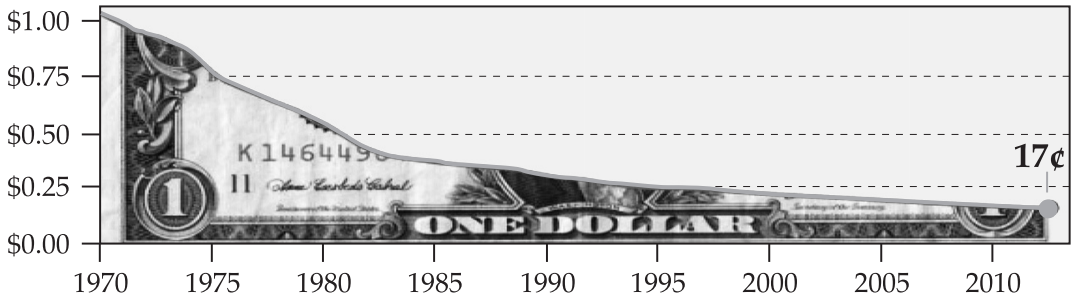

Nota: Dollar deflated by CPI, $1971=\$ 1.00$.

Fuente: Bureau of Labor Statistics.

25 Ron Paul (2012). 
GRÁFICO 22

VALOR EN DÓLARES USA DEL TOTAL DE ACTIVOS EN RESERVAS INTERNACIONALES

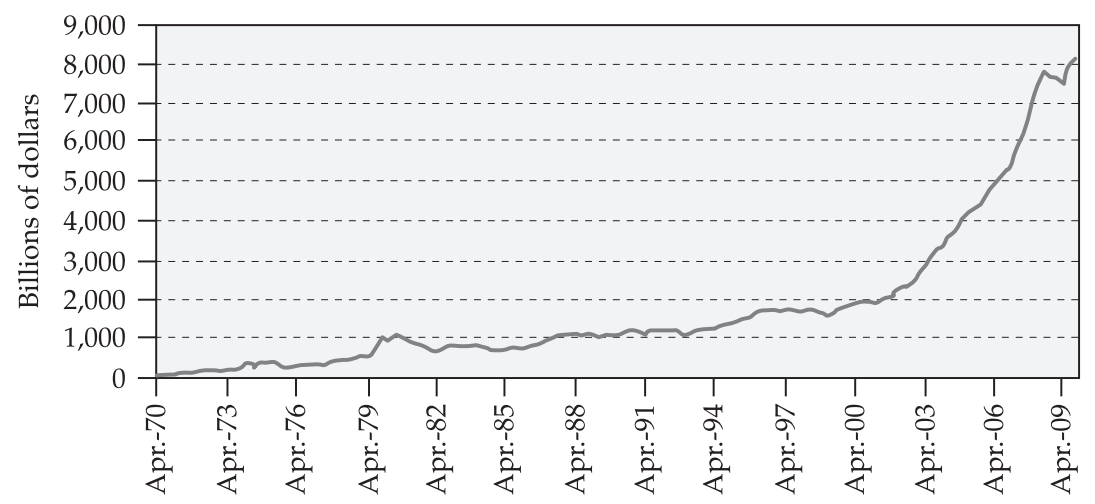

GRÁFICO 23

PORCENTAJE DE LAS MISMAS EN ORO

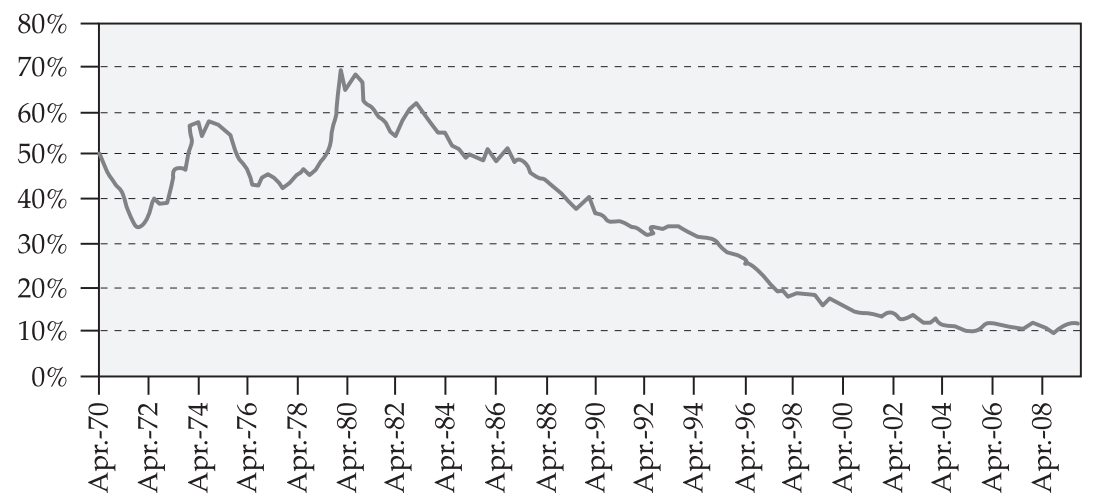

No es exclusivo del dólar estadounidense. La pérdida de poder adquisitivo en distintas divisas sin respaldo de activos reales en las últimas décadas ha sido evidente también y totalmente vinculada al aumento de la cantidad de las mismas en circulación a través de la política monetaria de los bancos centrales correspondientes (Gráfico 24).

Podemos concluir que es un hecho que el precio del oro sirve como cobertura ante las devaluaciones de las divisas, especial- 


\section{GRÁFICO 24}

\section{CAPACIDAD ADQUISITIVA VS CANTIDAD EN CIRCULACIÓN DE DISTINTAS DIVISAS}
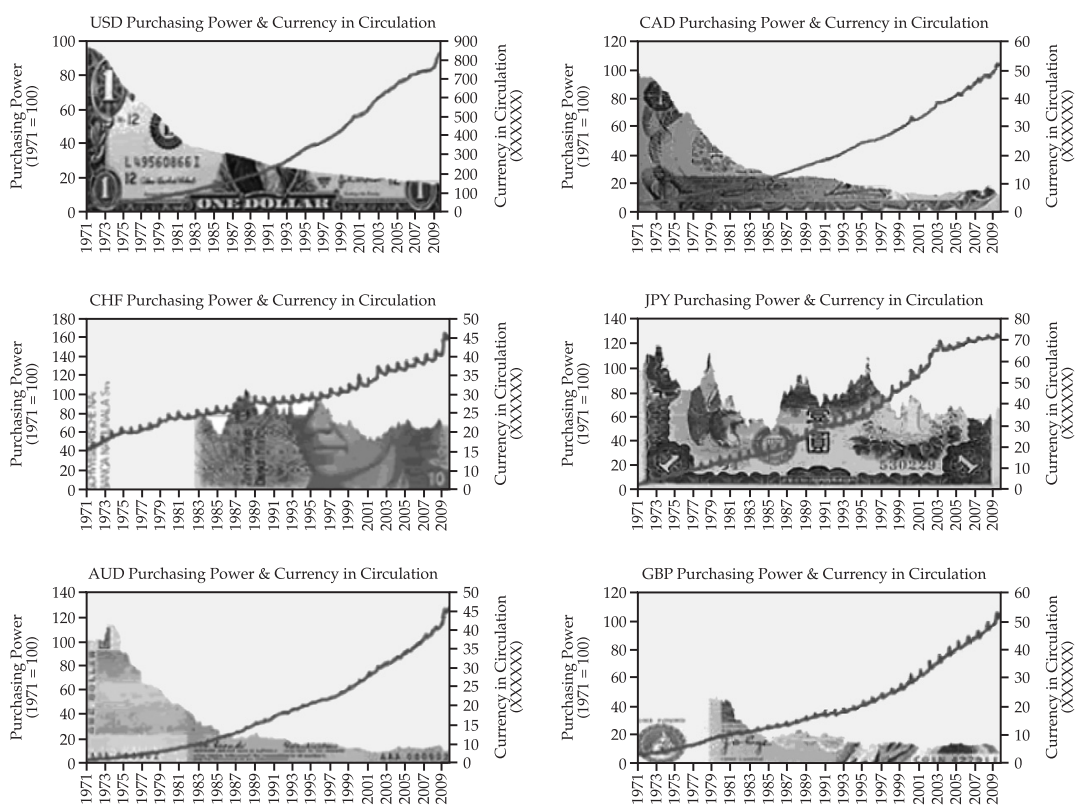

mente del dólar estadounidense, siendo por tanto la relación entre el precio de las divisas y el del oro inversa (Gráfico 25).

\section{La oferta y la demanda de oro}

Los últimos factores que vamos a analizar y que son también determinantes de la evolución del precio del oro son la oferta y la demanda.

La demanda de oro anual es de aproximadamente 3.500 toneladas. Existen tres tipos de demandantes de oro: la industria y la dental, el sector de la joyería y la demanda de inversión. La demanda en los últimos años se mantiene relativamente estable, aunque ha crecido un poco desde el estallido de la crisis en 2007. El mayor porcentaje lo demanda el sector joyero, aunque desde el año 2008 la demanda de inversión se ha incrementado notable- 
GRÁFICO 25

CORRELACIÓN INVERSA ENTRE INDEX DÓLAR Y PRECIO DEL ORO

Inverted scale

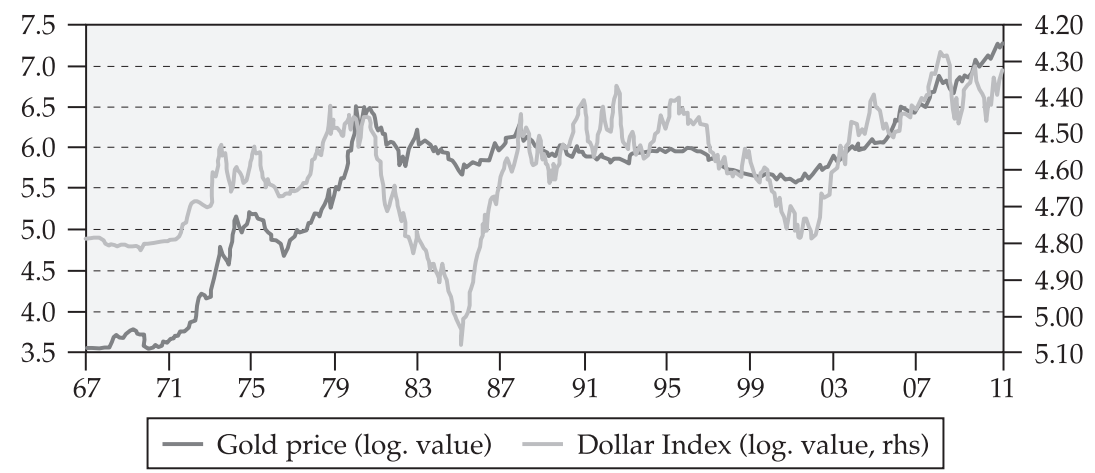

mente y tiene un peso creciente. En lo que respecta al sector industrial y dental su peso relativo es pequeño y decreciente debido al alto precio y a la búsqueda de bienes sustitutivos. ${ }^{26}$ (Gráfico 26).

GRÁfico 26

COMPOSICIÓN DE LA DEMANDA DE ORO

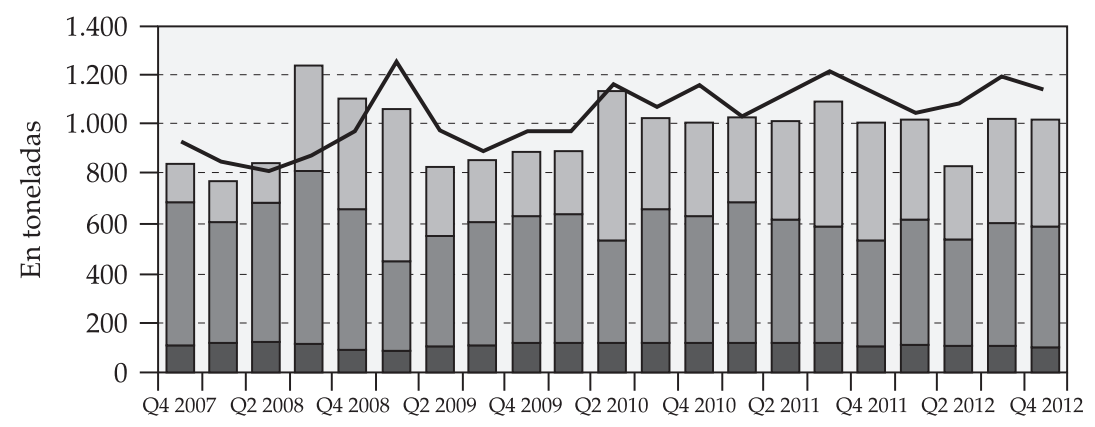

Industrial \& dental demand

Investment demand

Jewellery demand Total gold supply

${ }^{26}$ Joe Prendergast, Marcus Hettinger, Tobiar Merath, Karim Cherif, Stefan Graber, Dr. Bernd Berg, Koon How Heng y Anna-Maria Simon (2012). 
La demanda está fuertemente condicionada por la estacionalidad. Normalmente el periodo donde es más fuerte suele tener lugar a partir de septiembre, que es cuando el sector joyero aumenta sus pedidos coincidiendo con el festival hindú de las luces o Diwali, que comienza en Noviembre (Gráfico 27).

La demanda del sector joyero sigue siendo la más importante pero cada vez lo es menos debido a los altos precios. Desde el año 2008 el relevo lo ha tomado la demanda de inversión, que es menos sensible a los precios elevados y dos son principales agentes explicativos de esta: los bancos centrales y los fondos cotizados o ETFs. En primer lugar los bancos centrales de países emergentes se han convertido en compradores de oro a partir del estallido de la crisis financiera del 2007. Los bancos centrales de las economías avanzadas han mantenido sus reservas desde el estallido de la crisis, aunque antes de que se produjese esta, todos los bancos centrales eran vendedores netos de oro. (Gráficos 28 y 29).

Los bancos centrales tienen oro en sus carteras por motivos de diversificación, por seguridad económica, ante la incertidumbre, por confianza de la población hacia este activo y como cobertura

GRÁFICO 27

PATRONES ESTACIONALES HISTÓRICOS DEL PRECIO DEL ORO (1982-2011)

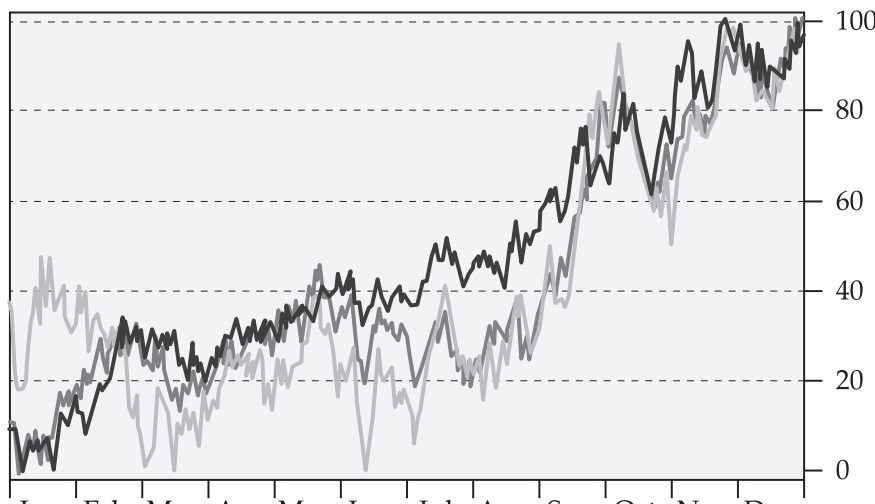

Seasonal High

Jan. Feb. Mar. Apr. May. Jun. Jul. Aug. Sep. Oct. Nov. Dec.

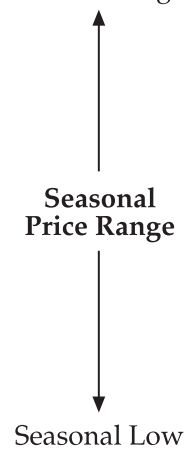

30 Yr Pattern - 15 Yr Pattern -5 Yr Pattern

Fuente: Moore Research Center, Inc. 
GRÁFICO 28

COMPRAS DE BANCOS CENTRALES

(En toneladas)

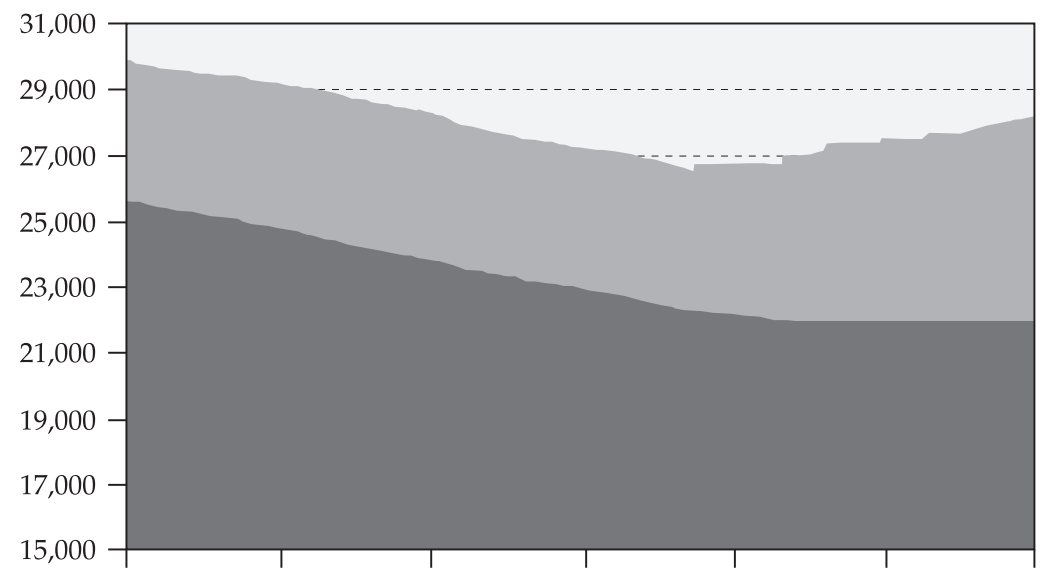

$\begin{array}{llllll}\text { Aug.00 Aug.02 Aug.04 Aug.06 Aug.08 Aug.10 Aug. } 12 & \text { An }\end{array}$

Advanced economies $\square$ Emerging and developing economies

Fuente: IMF, Bloomberg, Credit Suisse.

GRÁFICO 29

DEMANDA DEL SECTOR JOYERO

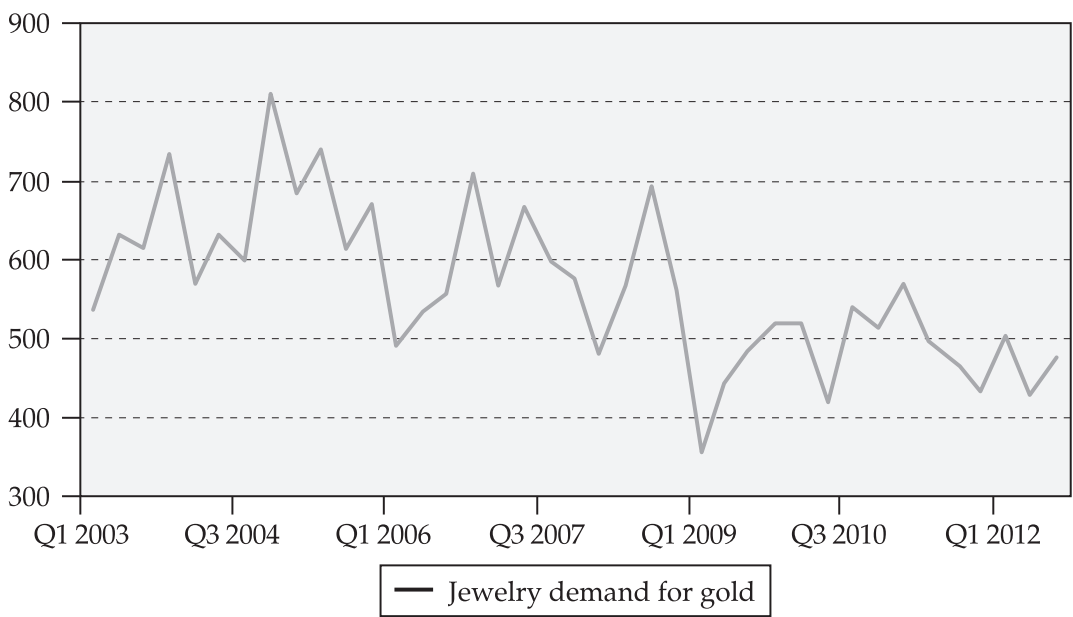

Fuente: World Gold Council, Credit Suisse. 
de otros activos. Las dos causas fundamentales son los tipos de interés reales negativos y la ausencia de riesgos de contrapartida. Cuando los tipos de interés reales son bajos o negativos la inversión en oro es atractiva debido al incremento de las expectativas de inflación y de devaluación. Por otro lado la posesión de lingotes, en momentos donde la sostenibilidad de la deuda soberana está en cuestión, ayuda a diversificar y protegerse ante los riesgos de quiebras y quitas (riesgos de contraparte). El promedio mundial de reservas de oro en los bancos es de un $10 \%$, pero los principales bancos centrales conservan un porcentaje más alto, mientras que los de países emergentes mantienen un porcentaje mucho más bajo.

Los fondos cotizados o ETFs, que normalmente tienen respaldo de oro físico (al menos los más importantes de la industria), se están convirtiendo en actores fundamentales en la evolución de su precio. El saldo acumulado por estos instrumentos de inversión es muy importante. A principios del año 2013 los 12 ETFs más importantes acumulan inversiones superiores a los 100 billones de dólares estadounidenses (miles de millones europeos) y poseen más de 2.500 toneladas (Gráfico 30).

Los ETFs y los derivados aumentan la negociabilidad del activo, aunque especialmente estos últimos no están exentos de polémica ante la posibilidad de algunas manipulaciones de corto plazo en los precios. Los flujos experimentados a través de los ETFs afectan al precio del oro a corto plazo significativamente (Gráfico 31).

Por el lado de la oferta, la producción ha aumentado desde el año 2000. Desde el año 2006 la producción se ha incrementado aproximadamente un 3\% anual. Los mayores crecimientos han sido llevados a cabo por países emergentes, ya que la producción en mercados maduros como Sudáfrica, Australia, Perú y Estados Unidos se ha reducido desde el 2006 en 5 millones de onzas (155 toneladas). El crecimiento en la producción ha venido de la mano de China, Colombia, Méjico y Rusia, que en el mismo periodo han sumado 7,6 millones de onzas adicionales (236 toneladas) a la oferta en el mercado del oro. ${ }^{27}$

27 Joe Prendergast, Tobias Merath, Marcus Hettinger y Anna-Maria Simon (2011). 
GRÁFICO 30

TENENCIAS DE ORO FÍSICO Y DERIVADOS DE LOS ETFS

(En toneladas)

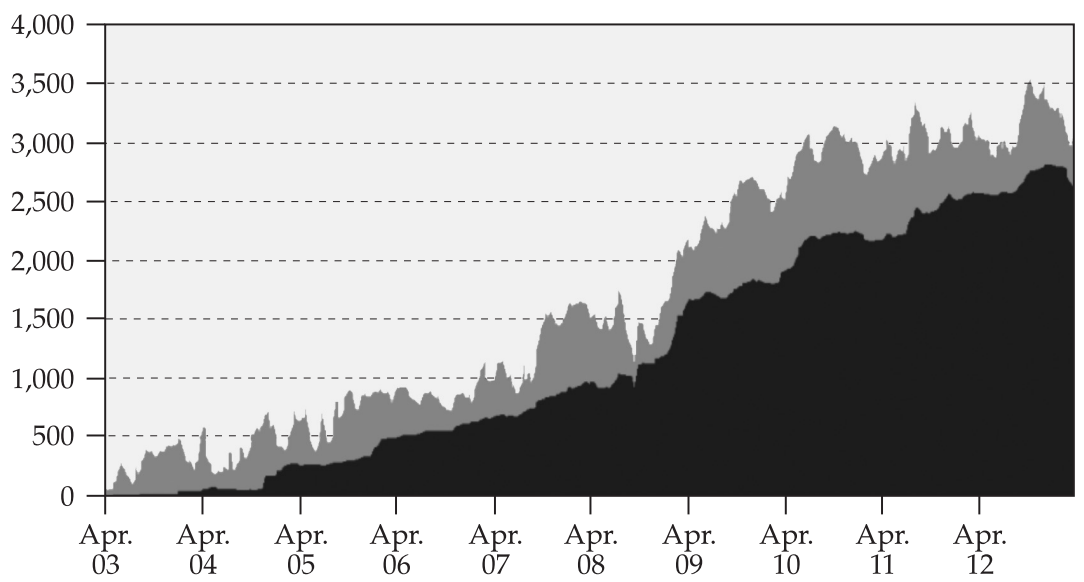

Gold holdings in physically backed ETFs

Non-commercial net long positions in futures and options markets

\section{GRÁFICO 31}

FLUJOS DE ENTRADA Y SALIDA EN ETFS

(En toneladas)

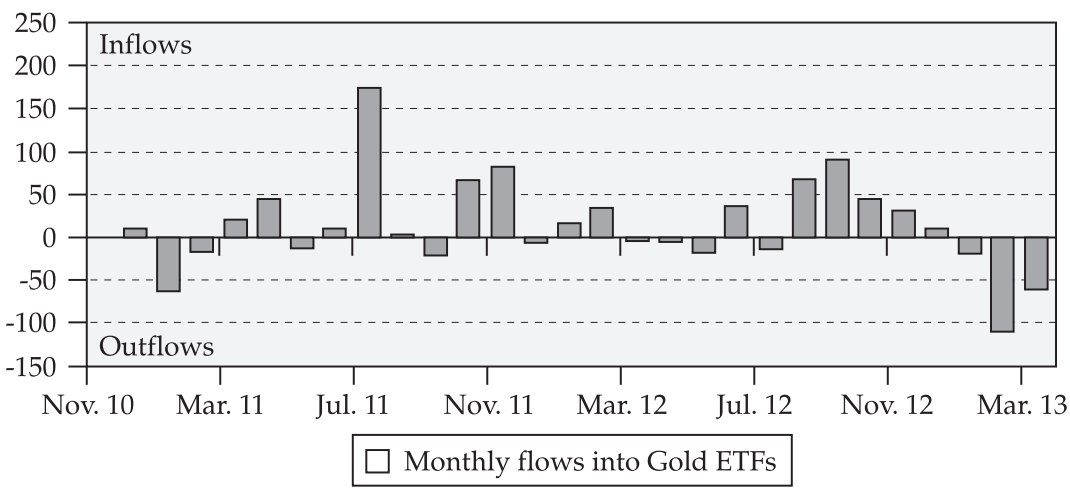

También la chatarra de oro se ha incrementado notablemente y ha contribuido al incremento de la oferta, ya que en una situación de crisis como la que atraviesan muchos países y regiones, 
es un activo líquido y valioso para familias y empresas en apuros (incluyendo las del sector joyero que han estado muy negativamente afectadas en países en crisis) (Gráfico 32).

Desde el año 2002 hasta el año 2009 se produjo una caída en la producción, pero los precios elevados han hecho posible la inversión rentable para muchos agentes del sector y ha contribuido al aumento de la oferta a pesar de las subidas de impuestos a los productores (Gráfico 33).

\section{III \\ EVOLUCION DEL PRECIO DURANTE LA GRAN RECESION}

La evolución del precio durante la Gran Recesión ha sido espectacular a pesar de las recientes caídas. Ningún activo ha tenido rendimientos positivos como los del oro de forma tan consistente. (Gráfico 34).

En el largo plazo hemos recordado como el precio del oro está relacionado con la inflación, con la devaluación de las divisas y con los tipos de interés que influyen de forma determinante en

GRÁFICO 32

OFERTA DE ORO POR TIPOLOGÍA

(En toneladas)

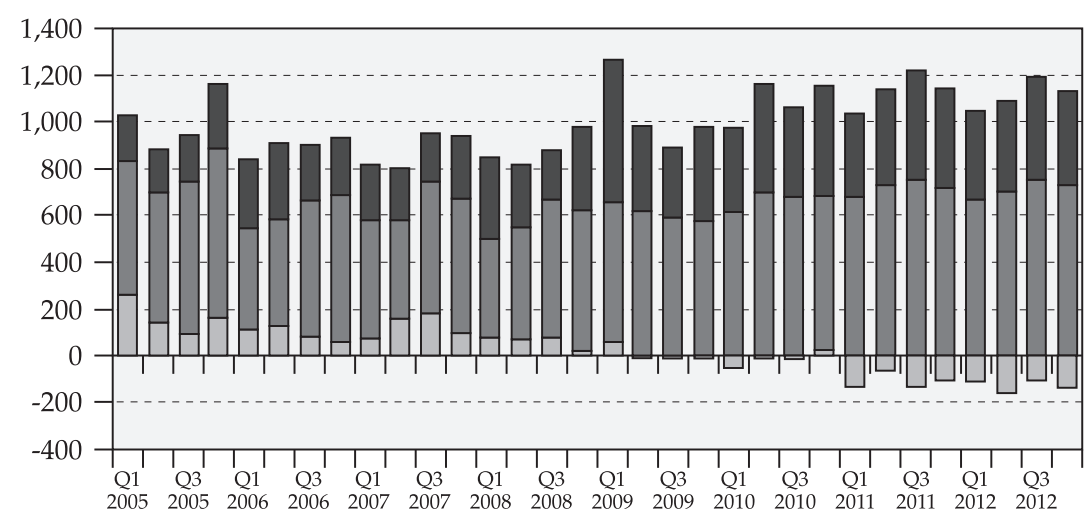

Official sector sales $\quad \square$ Total mine supply $\quad \square$ Old gold scrap 


\section{GrÁFICO 33}

PRODUCCIÓN MINERA VS PRECIO DEL ORO

(Producción en toneladas y precio en dólares/onza. $1 \mathrm{~kg}=32,15 \mathrm{oz}$ )

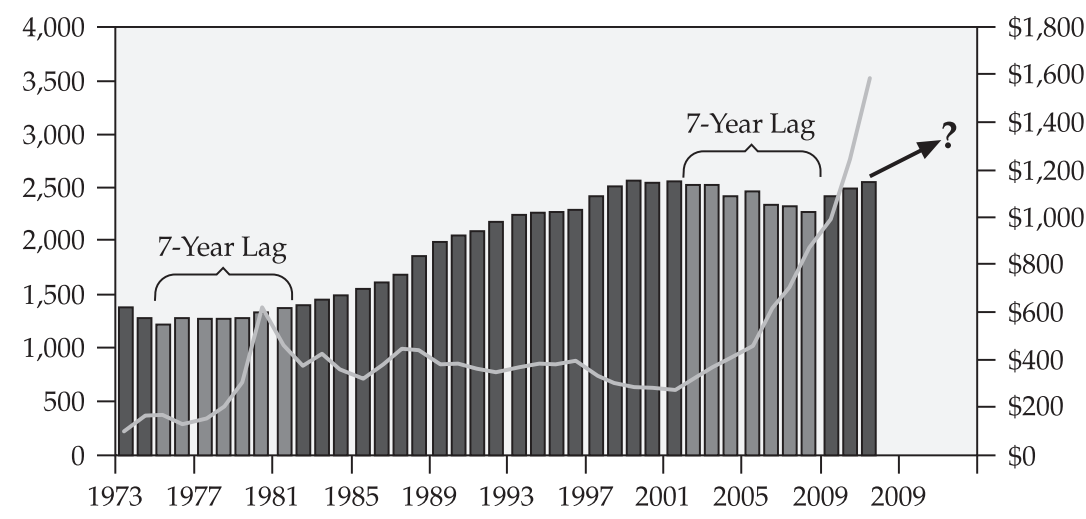

Mine Production in tons (left axis) - Gold Price in ounces (right axis)

Fuente: CPM Group, LBMA, World Gold Council.

GRÁFICO 34

PRECIO DEL ORO DURANTE LA GRAN RECESIÓN (Precio en dólares/onza. $1 \mathrm{~kg}=32,15 \mathrm{oz}$ )

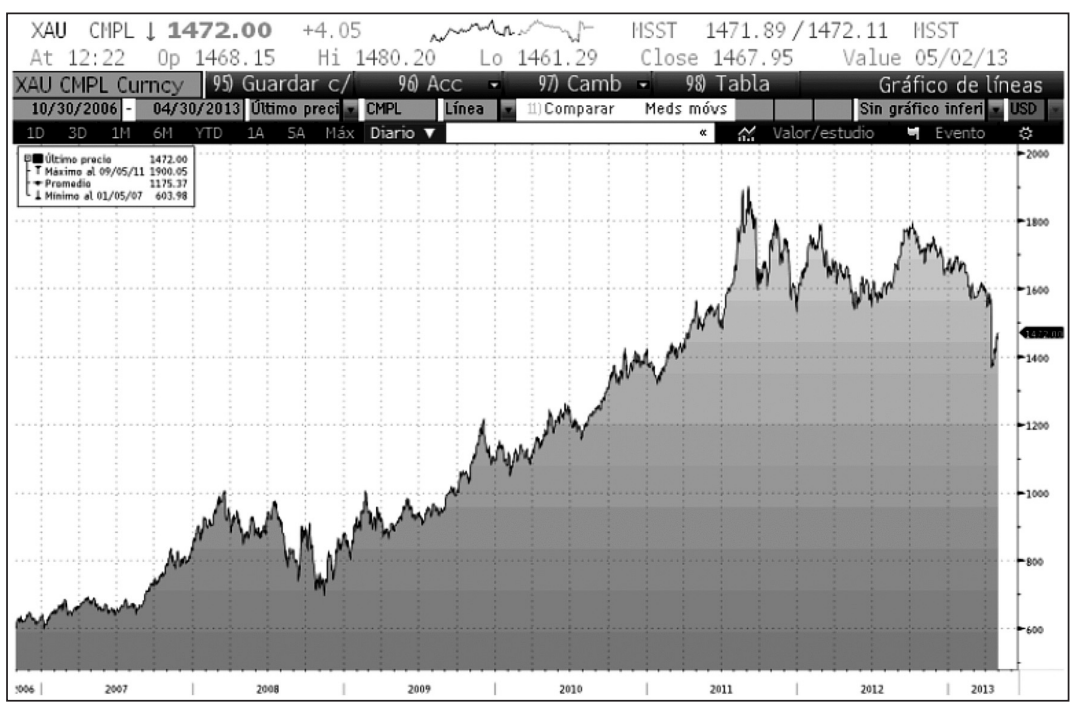


su demanda y oferta. A medio plazo los precios han estado y están fuertemente influenciados por el comportamiento de inversores e instituciones, a los que afectan el apetito por los activos de riesgo, las decisiones de los bancos centrales y la evolución de los precios de otros activos en sus respectivos mercados (renta fija, renta variable, divisas y materias primas). A pesar de que el oro no genere rentas su rendimiento ha batido a los índices de cualquier otro tipo de clase de activo (Gráfico 35).

Sin embargo, la volatilidad de su precio durante la Gran Recesión es comparable a la del mercado de renta variable, y por lo tanto superior a la del mercado de bonos o a las divisas, aunque menor que la de otros metales preciosos como la plata, el platino o el paladio.

Durante la Gran Recesión, la evolución del precio del oro ha estado vinculada, además de a los factores comentados anteriormente, de una forma directa y específica a las siguientes causas:

\section{GRÁFICO 35}

RENDIMIENTOS MEDIOS ANUALIZADOS Y VOLATILIDAD

(Datos en porcentaje. Media mensual anualizada de los últimos 10 años. Carteras rebalanceadas mensualmente)

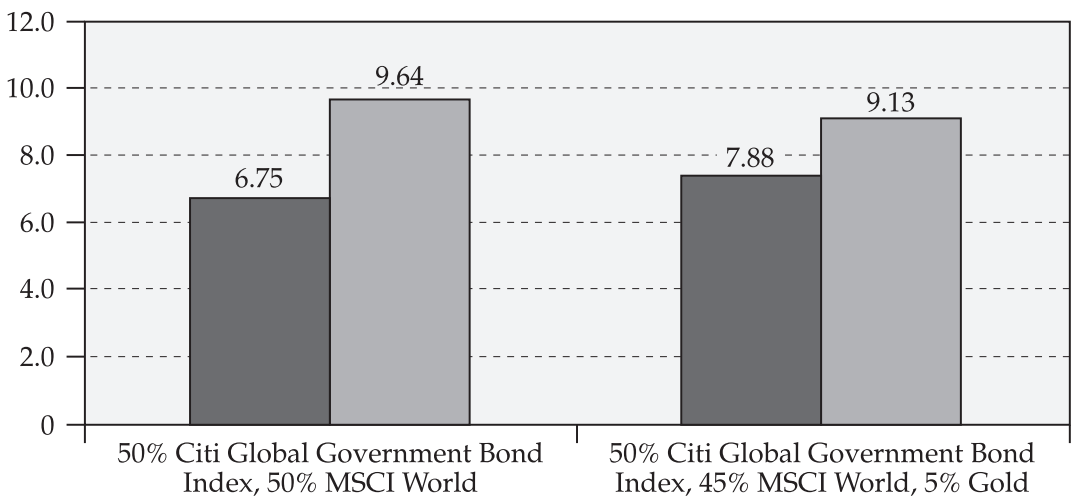

Annualized average monthly return $\square$ Standard Deviation 


\section{El endeudamiento fruto de los rescates bancarios y no bancarios}

Tras el estallido de la crisis, y especialmente tras la quiebra de Lehman Brothers en el año 2008, los gobiernos realizaron un enorme rescate principalmente a los bancos, para evitar su colapso. El origen de esta debilidad endémica está en la reserva fraccionaria y en la abolición de la Ley Glass-Steagall y el mercado OTC. También otras compañías recibieron ayudas de los gobiernos, pero la mayoría de los fondos fue a parar a los bancos. Estos rescates y ayudas gubernamentales se han realizado incrementando la deuda pública. De hecho en la actualidad existen 13 trillones de dólares estadounidenses más que a principios de 2008 a través de nuevas emisiones de deuda soberana. Los bonos AAA se han reducido desde el 2008 hasta el 2013, desde el 68\% hasta el 52\% en emisores soberanos (15 trillones de dólares americanos menos con calificación AAA). ${ }^{28}$

\section{Los planes de estímulo fiscales}

La deuda pública en buena medida se incrementó a través de estímulos fiscales y gasto público. Políticas keynesianas cortoplacistas que por un lado retrasaron el ajuste y por otro resultaron perjudiciales e improductivas, ${ }^{29}$ conllevando además del coste de oportunidad por la mala aplicación de esos recursos y el desincentivo para una reestructuración rápida de los sectores públicos y los estados del bienestar de muchos países ${ }^{30}$ (Gráfico 36). Shih.

${ }^{28}$ Carla Antunes da Silva, Amit Goel, Mohamed Souidi, Nick Gough y Justine

${ }^{29}$ FMI. (2012).

${ }^{30}$ Angel Martín Oro, Adriá Perez Martí y Juan Ramón Rallo. (2012). 
GRÁFICO 36

COMPARATIVA DEL TAMAÑO DE LOS ESTÍMULOS FISCALES

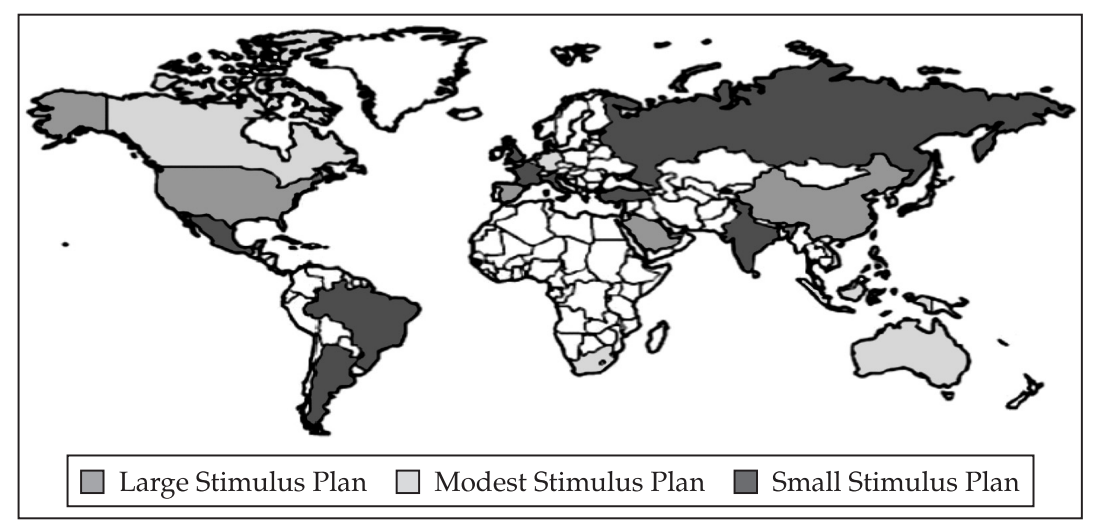

Fuente: «Understanding the G-20 Economic Stimulus Plans» (marzo de 2009, Brookings Institution.

\section{Las políticas monetarias heterodoxas de los bancos centrales}

Estos bancos centrales, a través de flexibilizaciones cuantitativas o laxitud en las quitas a los colaterales, han ayudado a evitar el colapso del sistema bancario y de la deuda pública y privada mediante políticas inflacionistas, la bajada artificial de los tipos de interés y devaluaciones competitivas. Con ello han consolidado un entorno de represión financiera, que se ha unido a la represión fiscal aplicada por los gobiernos tras el fracaso de los estímulos fiscales aplicados en la primera etapa de la crisis. ${ }^{31}$

Estas causas han generado en los agentes económicos elevadas expectativas de inflación y temor a un colapso del sistema monetario de reserva fraccionaria y papel moneda no convertible. La relación directa del precio del oro con la evolución del balance de la Reserva Federal o la relación inversa con las expectativas de inflación, expresadas a través del bono ligado a inflación de Estados Unidos a 10 años (TIPS) es manifiesta (Gráficos 37 y 38).

\footnotetext{
31 Jesús Huerta de Soto. (2012).
} 
GRÁFICO 37

RENDIMIENTO DE LOS BONOS LIGADOS A INFLACIÓN

EE.UU. A 10 AÑOS VS PRECIO DEL ORO

(En dólares/onza en escala invertida. $1 \mathrm{~kg}=32,15$ onzas)

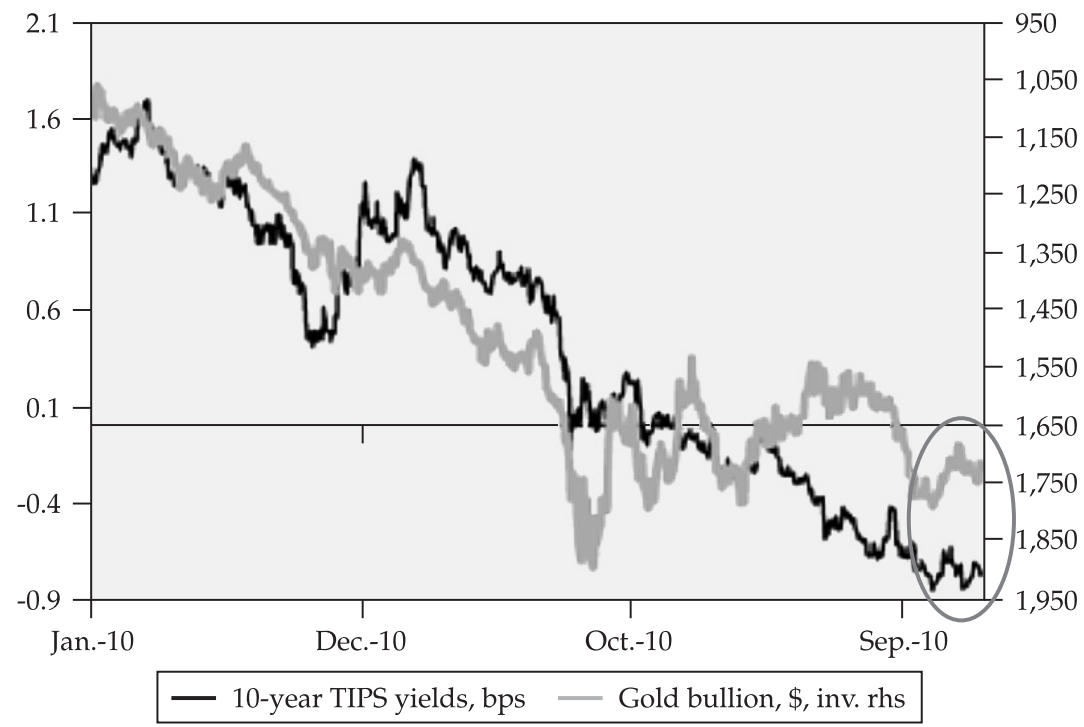

Fuente: Thomson Reuters, Credit Suisse research.

Se puede decir lo mismo de la relación directa del precio del oro con los incrementos de la masa monetaria.

Un papel esencial han tenido desde el año 2009 los bancos centrales de países emergentes, que ante las incertidumbres que plantea el papel moneda se han visto obligados a diversificar sus reservas de divisas. ${ }^{32}$ Por poner un ejemplo, el BCE decidió en el año 2000 que la proporción adecuada de reservas en oro era del 15\%. En 2013 todos los países emergentes tienen una proporción mínima de sus reservas en oro. Si los bancos centrales de estos países quisieran llegar a esos niveles deberían comprar 17.000 toneladas de oro en los próximos años, o el $40 \%$ de la producción anual actual (que serían unas 1.000 toneladas al año) durante los próximos 17 años (Gráfico 39).

${ }^{32}$ Andrew Garthwaite, Marina Pronina, Mark Richards y Sebastian Raedler. (2012). 


\section{GRÁFICO 38}

PRECIO DE LA ONZA DE ORO EN DÓLARES VS TAMAÑO

DEL BALANCE DE LA RESERVA FEDERAL

(Balance en billones de dólares. $1 \mathrm{~kg}=32,15$ onzas)

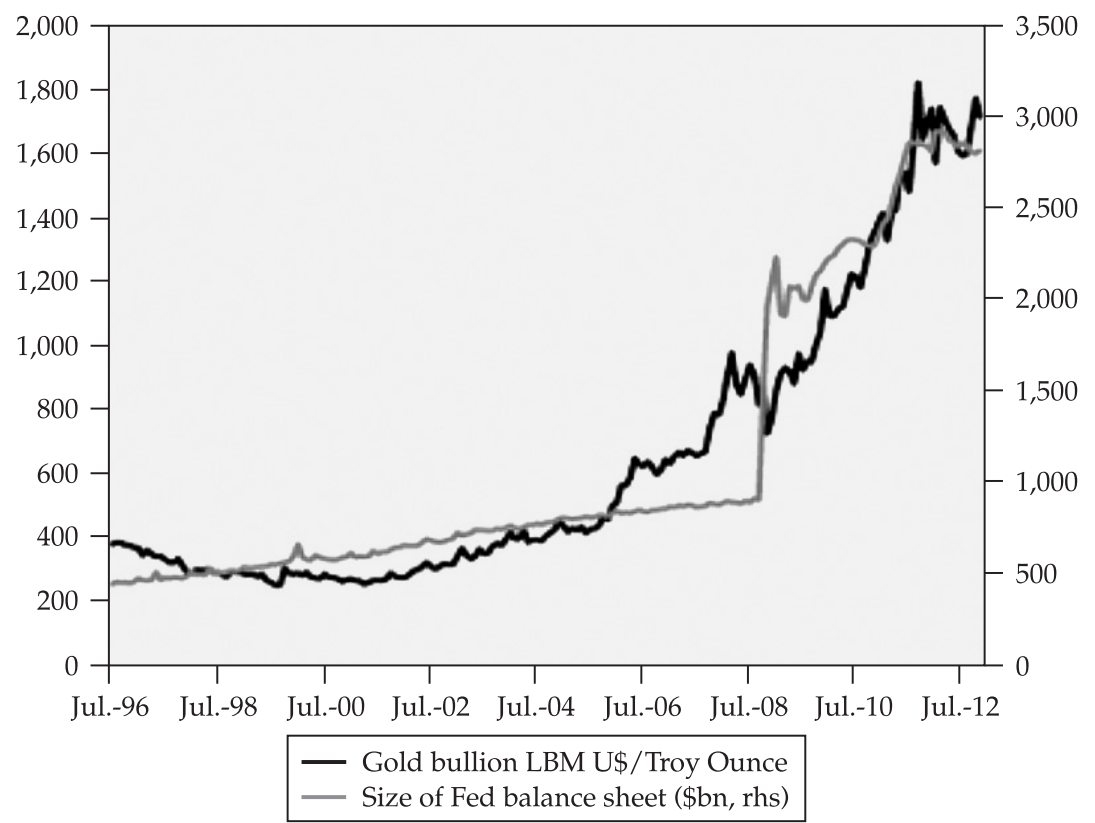

Fuente: Thomson Reuters, Credit Suisse research.

También es cierto que las posiciones especulativas son mayores ahora que cuando empezó la Gran Recesión aunque no tengan impacto en la demanda física de oro, pero afectan a su precio en el corto plazo.

En la actualidad se puede invertir en oro mediante la compra física en el mercado de contado de monedas o de lingotes; mediante futuros, que es la forma más habitual por los agentes financieros con motivo del apalancamiento (a pesar del contango y el «roll over» que hay que realizar frecuentemente para evitar la entrega física); a través de fondos cotizados o ETFs, la mayor parte de ellos respaldados por oro físico; las cuentas nominativas y cuentas numeradas, en estas últimas el inversor está expuesto a riesgo de contraparte porque el banco puede arrendar su oro; los derivados 
GRÁFICO 39

TENENCIA DE ORO EN MANOS DE BANCOS CENTRALES

E INCREMENTO POTENCIAL DE RESERVAS

EN PAÍSES EMERGENTES

(En toneladas)

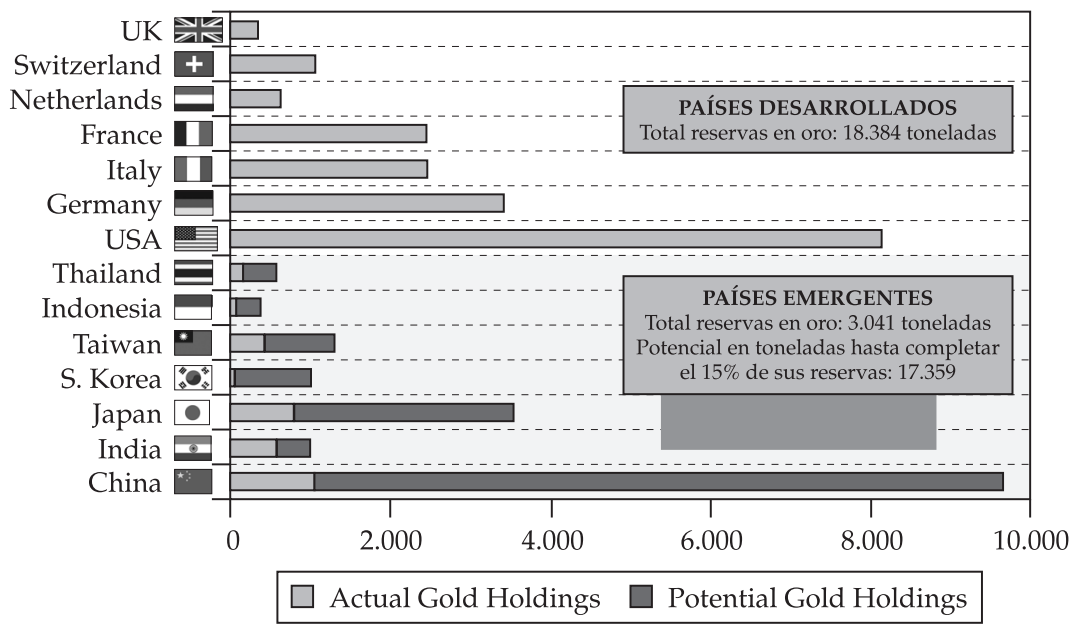

Fuente: IMF, IFS, World Gold Council.

estructurados, que tienen riesgo de contraparte con el emisor del mismo y suelen utilizar productos OTC como opciones o swaps; y los fondos de inversión, que suelen invertir a través de la compra de acciones de compañías mineras.

Todos estos instrumentos de inversión han condicionado la evolución del precio del oro durante la Gran Recesión, y en ocasiones han sido los causantes de caídas profundas en su precio, como las ocurridas en el año 2008 y en la primavera del año 2013.

La caída abrupta del precio en 2008 se debió esencialmente a la congelación del mercado de renta fija por la quiebra de Lehman Brothers. En ese momento, todos los operadores tuvieron que hacer frente a la situación de falta de negociabilidad vendiendo masivamente todos los activos negociables disponibles, como son las acciones o el oro. Sin embargo, a partir de ese momento, se intensificó la demanda física de oro que dio lugar a un aumento paulatino y muy significativo del precio del oro en los siguientes meses y años debido a todos los motivos anteriormente explicados. 
La caída del precio en 2013 es bastante más compleja de explicar. A los bancos centrales, y especialmente a la Reserva Federal no le interesa un excesivo optimismo en la renta variable que haga posible una presión vendedora en los bonos del Tesoro, lo que encarecería la financiación de su gobierno, que tiene problemas de déficit y deuda difíciles de solventar. En toda la Gran Recesión ha habido un "canario en la mina» y un "chivato" continuo de las políticas monetarias inmorales de un sistema monetario difícilmente calificable, ese canario y chivato ha sido el oro. Varios bancos de inversión recomendaron la venta poco antes de las caídas (Goldman y JP Morgan) y como la proporción negociada en los mercados a través de derivados es muy superior a la de oro físico, se puede manipular el precio a corto plazo si se tiene dinero suficiente. Nadie duda de que estos bancos de inversión tienen esa capacidad, y parece claro que provocaron la ruptura del soporte que tenía el precio del oro en los 1.500 dólares por onza (48.225 dólares por kilogramo). Dado el tipo de productos que se manejan en el mercado del oro y ante un evento de estas características, en cuanto se rompió el soporte, saltaron muchas ordenes de «stop loss» y se subieron las garantías de cobertura para futuros, provocando un pánico de mercado con ventas masivas y cierres de posiciones alcistas (que presionan a la baja el precio). Mientras que los especuladores vendían los comerciantes, especialmente los asiáticos, han aprovechado la caída abrupta del precio hasta los 1.320 dólares por onza (42.438 dólares por kilogramo) para comprar.

A pesar de todo esto, parece difícil que el oro no vaya a tener un papel importante como arbitro o incluso juez del sistema monetario en un futuro.

Juegan un papel esencial en todas las controversias que tienen lugar desde el 2008 los bancos centrales. Una de ellas es evitar la escalada de su precio para no generar desconfianza sobre el sistema fiduciario. Alquilando sus reservas de oro mediante contratos o físicamente, parece que pueden ofrecer al mercado oro, sacarle rentabilidad y evitar subidas en el precio. Sin llegar a vender, el banco central saca un rendimiento. Si el que se lo alquila es un banco comercial, este puede crear coberturas para mineras, cederlo a ETFs o aportarlo como colateral para conseguir liquidez por el $100 \%$ de 
su valor. Noticias como la petición de repatriación del oro de países como Alemania, añaden incertidumbre al asunto y condicionan fuertemente la evolución del precio. La reciente petición del Bundesbank a la Reserva Federal que custodia el $66 \%$ de sus reservas y el secretismo de la FED, es la prueba de que en el futuro la evolución del precio estará sometida a mucha incertidumbre. Seguramente la siguiente fórmula explicará buena parte de lo que pase:

$\frac{1 \text { tonelada de oro }}{1 \text { dólar EE.UU. }}=f\left(\frac{\text { Base monetaria en dólares } \times \text { Multiplicador del dólar }}{\text { Existencias de oro en circulación } \times \text { Multiplicador del oro }}\right)$ (Existencias en toneladas)

IV CONCLUSIONES

El sistema monetario actual adolece de activos reales que lo respalden. La fiducia pura concede un poder desproporcionado tanto a los gobiernos, que controlan los bancos centrales, como al sistema bancario y los grupos de poder. En el ámbito monetario estas elites de poder actúan sin rendir cuentas a la opinión pública. Tal concentración de poder es una de las mayores amenazas que se ciernen sobre el ser humano libre y sobre la institución social del mercado libre, y por ello debemos plantearnos seriamente el sentido de las instituciones coercitivas que condicionan la evolución de la economía y la vida de miles de millones de personas. El oro tiene en este proceso un papel fundamental que cumplir, como refleja su evolución tras el estallido de la Gran Recesión y los postulados defendidos históricamente por los economistas de la Escuela Austriaca, L. von Mises, F. von Hayek y J. Huerta de Soto entre otros.

El oro ha demostrado ser eficaz para protegerse contra la inflación monetaria, la devaluación de las divisas, los riesgos sistémicos y las incertidumbres futuras de carácter económico, político, social y militar.

Es vital enfrentarse al excesivo endeudamiento y a la opacidad del sistema financiero que amparan los estados y los bancos centrales manteniendo el privilegio que permite al sistema bancario desarrollar su actividad con ratios de capital inaceptables para 
cualquier otro sector de la economía. Los problemas de solvencia y liquidez, la repignoración de activos y los inmensos nocionales con o sin contraparte fuera de los balances de los bancos entrañan un enorme riesgo para la economía de mercado y el sistema capitalista que tantos beneficios han procurado a toda la sociedad. Los bancos centrales asumen un poder excesivo como artífices de la red que protege la intrínseca y extraordinaria debilidad del sistema bancario, incitando la toma de riesgos demasiado elevados del mismo, especialmente cuando se trata de entidades «demasiado grandes para quebrar» debido a su riesgo sistémico, y obligando así a los estados y al propio banco central a asumir la responsabilidad de evitar el colapso de todo el sistema monetario repercutiendo el coste a la mayoría de la sociedad. La reserva fraccionaria del $100 \%$ y los «bail in» reducirían estos riesgos significativamente, pero el oro deberá ser el árbitro o estos los cambios regulatorios actuales serán manifiestamente insuficientes para evitar la creación de burbujas y sus terribles consecuencias. Las regulaciones y las medidas que se están implementando durante la Gran Recesión adolecen de falta de criterio verdaderamente económico y corren el riesgo de imposibilitar el ajuste necesario en los balances de todos los agentes económicos, además de desincentivar un comportamiento verdaderamente ético. Los bancos deberían poder quebrar como cualquier otra empresa de cualquier sector sin contagiar con sus consecuencias a otros bancos y a toda la estructura productiva de la economía. El mecanismo que puede llevar a cabo de la forma mas eficaz posible esta necesaria disciplina solo puede ser el libre mercado en el marco de los principios generales del derecho y sobre el fundamento del oro como verdadera institución social evolutiva del dinero.

En el ámbito moral las principales amenazas son tres: el trasvase de valor del acreedor al deudor, la impunidad de los responsables y la socialización de las pérdidas.

Es recurrente el uso de la inflación y la consiguiente devaluación llevada a cabo por los responsables de la política económica, práctica inmoral a todas luces. Con la devaluación y la inflación se produce un trasvase de valor del acreedor al deudor (el sistema bancario, los gobiernos y las grandes empresas multinacionales son los agentes más endeudados). El perjuicio y las pérdidas por 
la reducción de valor en los ahorros de los agentes que han sido mas prudentes o previsores en la etapa previa de burbuja se convierte en beneficio para los insolventes o excesivamente endeudados que ven reducido en términos relativos el valor de sus deudas.

La impunidad e irresponsabilidad es otra de las consecuencias de los vínculos hegemónicos que impone el intervencionismo creciente, y se convierten en un estímulo para las peores prácticas de los agentes económicos (especialmente de los agentes más ligados al poder hegemónico). Algunas empresas, gobiernos y bancos que han asumido riesgos excesivos no asumirán la responsabilidad por haberse convertido en instituciones «demasiado grandes para caer».

La socialización de las pérdidas es otra consecuencia inevitable en el actual sistema monetario y un enorme riesgo moral. Que los beneficios sean privados y las pérdidas traspasadas a los contribuyentes es inaceptable intelectualmente para cualquier persona con principios y sentido común.

La importancia del oro como valor refugio, como cobertura contra la inflación, como protección frente a la devaluación, y en definitiva como bien presente y medio de intercambio evolutivamente convertido en la institución social del dinero por excelencia es, y así lo ha reflejado su precio durante la Gran Recesión, parte de la solución a los problemas de nuestro sistema monetario y bancario, además de una garantía moral frente a los desmanes del poder hegemónico que tanto condiciona a la sociedad libre a través del monopolio de la institución del dinero.

\section{REFERENCIAS BIBLIOGRÁFICAS}

Allen, W., and Moesser, R., (2012): «The liquidity consecuences of the euro area sovereign debt crisis», Bank of International Settlements, November 2012, found at http: / / www.bis. org/publ/work390.pdf.

Andros, T., (2012): «2012 Outlook, part 1: When leverage fails», January 2012, found at http:/ / www.24hgold.com/english/ contributor.aspx ?article $=3791034326$ G10020\&contributor $=$ Ty+Andros. 
Banco de Pagos Internacionales (2012a): «82.․ Informe Anual», Banco de Pagos Internacionales, Junio de 2012, http: / / www. bis.org/publ/arpdf/ar2012_es.pdf.

- (2012b): «Aspectos mas destacados de las estadísticas internacionales del BPI ${ }^{1} »$, Informe trimestral del BPI, Junio 2012, http://www.bis.org/publ/qtrpdf/r_qt1206b_es.pdf.

BANK OF ENGLAND (2012): «The distributional effects of asset purchases», Bank of England, July 2012, found at http:/ / www. bankofengland.co.uk/publications/Documents/news/2012/ nr073.pdf.

Beffy, P., De Montchalin, A. and KaK. R., (2012): «10 questions on Spain», Exane BNP Paribas Global Economics Research and Investment Strategy, April 2012.

Comptroller of the Currency Administrator of National Banks (2012): «OCC's quarterly report on bank trading and derivates activities second quarter 2012», U.S. Department of the Treasury, July 2012, found at http: / / www.occ.gov / topics / capital-markets/financial-markets/trading/derivatives / dq212.pdf.

Da Silva, C., Goel, A., Souidi, M., Gough, N., and ShiH, J., (2012): «Reshaping European Banks. Back to basics», Credit Suisse Equity Research, June 2012, found at https: / / doc.researchand-analytics.csfb.com/docView?language $=$ ENG\&source $=$ emfromsendlink\&format=PDF\&document id=978431241\& extdocid=978431241_1_eng_pdf\&serialid=TO0KnF2gOR\%2 b6OXQNQ6ojyv5SnoTpWPOGbq5TsH\%2bPgig\%3d.

EL-ERIAN, M., (2012): «Evolution, impact and limitations of unusual central bank policy activism», PIMCO Viewpoint, April 2012, found at http:/ / research.stlouisfed.org/publications / review /12/07/243-264El-Erian.pdf.

FILARDO, A., and YETMAN, J., (2012a): «The expansion of central bank balance sheets in emerging Asia: what are de risks?», Bank of International Settlements. Quarterly Review. June 2012, found at http:/ / www.bis.org/publ/qtrpdf/r_qt1206g.pdf

- (2012b): «Key facts on central bank balance sheets in Asia and the Pacific», Bank of International Settlements, October 2012, found at http:/ / www.bis.org/publ/bppdf/bispap66c_ rh.pdf. 
Garthwaite, A., Pronina, M., Richards, M., and Raedler, S., (2012a): «What to do when we get synchronized QE», Credit Suisse Global Equity Strategy, March 2012.

- (2012b): «Global equity strategy. China: money talks louder than PMIs», Credit Suisse Equity Research, May 2012, found at https:/ /doc.research-and-analytics.csfb.com/docView? language $=\mathrm{ENG} \&$ source $=$ emfromsendlink $\&$ format $=\mathrm{PDF} \&$ document_id $=973899241 \&$ serialid $=5$ sOWxFktU0BqHef TFO\%2BnUXfHTJnGTL8NlmwksfOg1fk\%3D.

Gross, B., (2012): «What's in a name», PIMCO Investment Outlook, July 2012, found at http:/ / www.pimco.com/en/insights / pages/whats-in-a-name.aspx.

HolmES, F., (2012): «What's driving gold companies?», U.S. Global Investors, November 2012, found at http: / / www.usfunds. $\mathrm{com} / \mathrm{media} /$ files/pdfs/researchreports / 2012-researchreports/USGlobalInvestors-Gold_Special_Report.pdf.

Huerta de Soto, J., (1998): Dinero, Crédito Bancario y Ciclos Económicos, Madrid, Unión Editorial [5. ed edición, 2011].

- (2012): «En defensa del Euro: un enfoque austriaco (con una crítica a los errores del B.C.E. y al intervencionismo de Bruselas)», Mayo 2012, http:/ / s.libertaddigital.com/doc/ jesus-huerta-de-soto-en-defensa-del-euro-un-enfoqueaustriaco-41912626.pdf. Procesos de Mercado, vol., IX, n. ${ }^{\circ}$ 1, primavera 2012, pp. 15 a 49.

INTERNATIONAL MONETARY Fund (2012): «Spain: Financial Stability Assessment», International Monetary Fund, June 2012, found at https://www.imf.org/external/pubs/ft/scr/2012/ cr12137.pdf.

Kendall, T., (2012): «Precious metals conference 2012», Credit Suisse, November 2012.

Martín, A., Pérez, A., y Rallo, J.R., (2012): «Del espejismo de los estímulos a la falsa austeridad pública: la política fiscal ante la Gran Recesión», Boletín del observatorio de coyuntura económica del Instituto Juan de Mariana, Junio de 2012, http:/ / www. juandemariana.org/estudio/5463/espejismo/estimulos/ falsa/austeridad/publica/.

MARTínez, J.L., (2010): «Una mirada al oro como inversión», Citigroup, Abril 2010. 
Menger, C., (1983): Principios de economía política, Madrid, Unión Editorial.

Merath, T., TANNER, E., and Braber, S., (2010): «Investment Ideas: A primer on precious metals», Credit Suisse, May 2010.

Merino, A., (2012): «Perspectivas macroeconómicas: escenario central y crisis Zona Euro», Dirección de estudios y análisis del entorno de Repsol, Julio 2012.

Mises, L. von (1994): La acción humana, Madrid, Unión Editorial.

PAUL, R., (2012): «How long will the Dollar remain the world's reserve currency?», September 2012, found at http:// www.infowars.com/ron-paul-how-long-will-the-dollarremain-the-worlds-reserve-currency/.

Prendergast, J., Merath, T., Hettinger, M., and Simon, A.M., (2011): «What drives precious metals prices?», Credit Suisse, April 2011.

Prendergast, J., Hettinger, M., Merath, T., Cherif, K., Graber, S., Dr. BERG, B., How, K., and SimON, A.M., (2012): «Gold and EUR/USD with some upside potential», Credit Suisse, November 2012.

Rothbard, M., (2000): Historia del Pensamiento Económico, Madrid, Unión Editorial.

RubLIN, L., (2012): «Barron's 2012 Roundtable, part one - Listen up, class: Here's how to profit», Barron's Cover. January 2012, found at http: / / online.barrons.com/article/SB500014240 52748703535904577152932179268296.html\#articleTabs_article\%3D1.

SchimL, M., (2013): «Asset Price Bubbles», April 2013. 